\title{
repisäarlud
}

This is the peer reviewed version of the following article:

EWS-FLI1-mediated suppression of the RAS-antagonist Sprouty 1 (SPRY1) confers aggressiveness to Ewing sarcoma.

Cidre-Aranaz F, Grünewald TG, Surdez D, García-García L, Carlos Lázaro J, Kirchner T, González-González L, Sastre A, García-Miguel P, López-Pérez SE, Monzón S, Delattre O, Alonso J.

Oncogene. 2017 Feb 9;36(6):766-776

which has been published in final form at

https://doi.org/10.1038/onc.2016.244 


\title{
repisälud
}

\section{EWS-FLI1-mediated suppression of the RAS-antagonist Sprouty 1 (SPRY1) confers aggressiveness to Ewing sarcoma.}

\author{
AUTHORS \\ Florencia Cidre-Aranaz ${ }^{1}$, Thomas G. P. Grünewald ${ }^{2,3}$, Didier Surdez ${ }^{2}$, Laura GarcíaGarcía ${ }^{1}$, José Carlos \\ Lázaro $^{1}$, Thomas Kirchner ${ }^{3}$, Laura González-González ${ }^{1}$, Ana Sastre ${ }^{4}$, Purificación García-Miguel ${ }^{4}$, Sara \\ E. López-Pérez ${ }^{1}$, Sara Monzón ${ }^{1,5}$, Olivier Delattre², Javier Alonso ${ }^{1}$. \\ ${ }^{1}$ Unidad de Tumores Sólidos Infantiles, Instituto de Investigación de Enfermedades Raras, Instituto \\ de Salud Carlos III, Majadahonda, Spain. \\ 2 \\ INSERM U830 "Genetics and Biology of Cancers", Institut Curie Research Center, Paris, France \\ ${ }^{3}$ Laboratory for Pediatric Sarcoma Biology, Institute of Pathology, LMU Munich, Munich, Germany. \\ ${ }^{4}$ Unidad hemato-oncología pediátrica, Hospital Infantil Universitario La Paz, Madrid, Spain. \\ ${ }^{5}$ Centro de Investigación Biomédica en Red de Enfermedades Raras (CIBERER U758), \\ Instituto de Salud Carlos III, Madrid, Spain
}

\section{Corresponding author}

Dr. Javier Alonso

Instituto de Salud Carlos III

Instituto de Investigación de Enfermedades Raras

Unidad de Tumores Sólidos Infantiles

Ctra. Majadahonda-Pozuelo km 2

Majadahonda (28220), Madrid, Spain

Phone: +34 918223217 FAX:

+34918223269

fjalonso@isciii.es 


\section{repisälud}

\section{Running title}

SPRY1 suppression confers aggressiveness to Ewing sarcoma

\section{Supporting information}

F.C-A., L.G-G., J.C.L., A.S., P.G-M., S.E.L-P., S.M., and J.A. are supported by Asociación Pablo Ugarte and Miguelañez S.A, ASION-La Hucha de Tomás, Fundación La Sonrisa de Alex and Instituto de Salud Carlos III (PI12/00816 and Spanish Cancer Network

RTICC RD12/0036/0027). T.G.P.G. is supported by a grant from 'Verein zur Förderung von Wissenschaft und Forschung an der Medizinischen Fakultät der LMU München

(WiFoMed)', the Daimler and Benz Foundation in cooperation with the Reinhard Frank Foundation, by LMU Munich's Institutional Strategy LMUexcellent within the framework of the German Excellence Initiative, the 'Mehr LEBEN für krebskranke Kinder - BettinaBräu-Stiftung', the Walter Schulz Foundation, the Fritz Thyssen Foundation (FTH40.15.0.030MN) and by the German Cancer Aid (DKH-111886). The "Genetics and Biology of Cancers" team (T.G.P.G., D.S., O.D.) is supported by grants from the Ligue Nationale Contre Le Cancer (Equipe labellisée). This work was also supported by the European PROVABES, ASSET and EEC FP7 grants. We also thank the following associations for their invaluable support: the Société Française des Cancers de l'Enfant, Courir pour Mathieu, Dans les pas du Géant, Olivier Chape, Les Bagouzamanon, Enfants et Santé and les Amis de Claire. We thank Dr. S. Navarro (university of Valencia, Valencia, Spain) and Dr. T.J. Triche (Children's Hospital Los Angeles, Los Angeles, USA) for provide us with Ewing sarcoma cell lines A4573 and TTC-466 respectively.

\section{Conflict of interest}

The authors declare no conflict of interest. 


\section{repisälud}

\section{ABSTRACT}

Ewing sarcoma is characterized by chromosomal translocations fusing the EWS gene with various members of the ETS family of transcription factors, most commonly FLI1. EWSFLI1 is an aberrant transcription factor driving Ewing sarcoma tumorigenesis by either transcriptionally inducing or repressing specific target genes. Herein, we showed that Sprouty 1 (SPRY1), which is a physiological negative feedback inhibitor downstream of fibroblast growth factor (FGF) receptors (FGFRs) and other RAS-activating receptors, is an

EWS-FLI1 repressed gene. EWS-FLI1 knock-down specifically increased the expression of SPRY1 while other Sprouty family members remained unaffected. Analysis of SPRY1 expression in a panel of Ewing sarcoma cells showed that SPRY1 was not expressed in Ewing sarcoma cell lines, suggesting that it could act as a tumor suppressor gene in these cells. In agreement, induction of SPRY1 in three different Ewing sarcoma cell lines functionally impaired proliferation, clonogenic growth and migration. In addition, SPRY1 expression inhibited ERK/MAPK signalling induced by serum and basic FGF (bFGF). Moreover, treatment of Ewing sarcoma cells with the potent FGFR inhibitor PD-173074 reduced bFGF-induced proliferation, colony formation and in vivo tumor growth in a dosedependent manner, thus mimicking SPRY1 activity in Ewing sarcoma cells. Although the expression of SPRY1 was low when compared to other tumors, SPRY1 was variably expressed in primary Ewing sarcoma tumors and higher expression levels were significantly associated with improved outcome in a large patient cohort. Taken together, our data indicate that EWS-FLI1-mediated repression of SPRY1 leads to unrestrained bFGF-induced cell proliferation, suggesting that targeting the FGFR/MAPK pathway can constitute a promising therapeutic approach for this devastating disease.

\section{Keywords}

EWS-FLI1, SPRY1, Ewing sarcoma, FGF, FGFR inhibitors INTRODUCTION

Ewing sarcomas are aggressive bone and soft-tissue sarcomas mostly affecting children and young adults ${ }^{1}$. Although the 5 -year survival in patients with localized disease increased significantly upon the addition of systemic chemotherapy to protocol treatments in the 70s80s ${ }^{2}$, the prognosis and survival of patients with metastatic or recurrent disease remained generally very poor ${ }^{3}$. Indeed, Ewing sarcoma features high rates of early metastasis with about $20 \%$ of patients having detectable metastases at diagnosis ${ }^{4}$.

The molecular hallmarks of Ewing sarcoma are nonrandom chromosomal translocations generating in-frame fusion of the $E W S$ gene on chromosome 22 and the carboxyl terminus of a member of the ETS family of transcription factors (i.e. FLI1, ERG, ETV1, FEV, ETV4, POU5F1) including the DNAbinding domain ${ }^{5}$ (reviewed in ${ }^{1}$ ). This fusion gives rise to aberrant EWS-ETS transcription factors, EWS-FLI1 being present in $85 \%$ of cases. 


\section{repisälud}

EWS-FLI1 induces massive deregulation of protein expression by either transcriptionally inducing or repressing specific target genes, many of which are involved in the oncogenic process ${ }^{6}$. For instance, EWS-FLI1 induces the expression of NROB1 (DAX1), EGR2, NKX2.2,CCK, PRKCB or STEAP1 789 1011 , while suppressing IGFBP3, LOX, DKKI or TGFBIIR ${ }^{12} 1314{ }^{15}$. All these genes have been shown to be important in Ewing sarcoma pathogenesis.

Here, we report on the tumor suppressive role of another repressed EWS-FLI1-targetd gene, namely Sprouty 1 (SPRY1), which is a negative feedback inhibitor of the

RAS/MAPK/ERK pathway downstream of the FGF receptor (FGFR).

SPRY1 is part of the mammalian Sprouty gene family consisting of four members (SPRY1 to 4), which share important sequence similarities ${ }^{16}$ such as a highly conserved cysteinerich domain in the Cterminal region (which is also found in the SPRED family of proteins) and a short amino acid sequence in the $\mathrm{N}$-terminus ${ }^{17}$. SPRY proteins differ largely in their tissue distribution, activity and interaction partners ${ }^{18}$, thus suggesting non-redundant functions. SPRY1 is an upstream antagonist of RAS that is activated by extracellular signal-related kinase (ERK), providing a negative feedback loop for RAS signaling. Of note, about one third of all human cancers are thought to carry a mutated $R A S$ gene that activates downstream signaling ${ }^{19}$. It has been suggested that SPRY1 may have a tumor suppressor function in specific tumors since its expression is decreased in several human cancers such as breast and prostate cancer 2021 22. Indeed, several studies showed that SPRY1 overexpression in tumor cell lines inhibits cell proliferation, migration and anchorage-independent growth in vitro 232124

In this study, we show that SPRY1 acts as a tumor suppressor in Ewing sarcoma cells, and that SPRY1 repression is necessary for cell proliferation and migration. Interestingly, SPRY1 repression was important to ERK pathway activation. Moreover, FGFR-inhibition mimicked SPRY1 effect on proliferation and growth, indicating that SPRY1 plays an important role in Ewing sarcoma. Finally, elevated SPRY1 expression correlated with improved overall survival of Ewing sarcoma patients and inversely correlated with metastasis at diagnosis. Collectively, our data indicate that EWS-FLI1mediated repression of SPRY1 confers a growth advantage to Ewing sarcoma cells and that SPRY1 levels constitute a novel biomarker for outcome prediction of Ewing sarcoma patients. Taken together these results suggest a rationale for targeting FGFR/SPRY1/RAS/MAPK/ERK pathway as a new therapeutic approach in this devastating disease.

\section{RESULTS}

\section{SPRY1 expression is strongly inhibited by EWS-FLI1 in Ewing sarcoma cell lines}

Analysis of a gene expression profile of A673 Ewing sarcoma cell line genetically modified to express a specific shRNA directed against EWS-FLI1 mRNA upon doxycycline stimulation (A673/TR/shEF) 


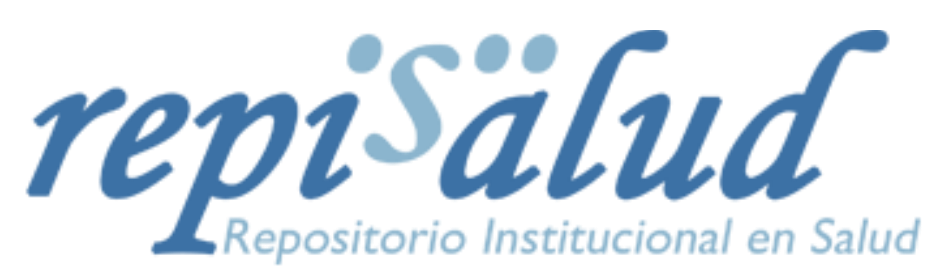

(Gene Expression Omnibus (GEO) accession code: GSE36007), indicated that SPRY1 is strongly down-regulated by EWS-FLI1. These microarray results were confirmed by RT-qPCR experiments. As depicted in Figure 1A, EWS-FLI1 knockdown led to a dramatic re-expression of SPRY1 mRNA (up to 1,000-fold compared to controls), while the mRNA levels of the other members of the SPRY family

(SPRY2, 3 and 4) were only minimally affected. Analysis of SPRY1 protein levels in the A673/TR/shEF cell model confirmed these results. As shown in Figure 1B, SPRY1 protein was undetectable by western blot in A673/TR/shEF grown in absence of doxycycline. However, a strong induction of SPRY1 protein was observed upon doxycycline-mediated EWS-FLI1 knockdown.

We next studied whether the inhibition of SPRY1 expression could be a common feature of Ewing sarcoma cells. We first analyzed the levels of SPRY1 mRNA and protein in a panel of eight Ewing sarcoma cell lines harboring different EWS-FLI1 or EWS-ERG fusion proteins (Supplementary Table 1). As shown in Figure 1C and 1D, SPRY1 mRNA and protein were undetectable in all Ewing sarcoma cell lines analyzed. Interestingly, the mRNA levels of the other members of the SPRY family were variably expressed in this panel of Ewing sarcoma cells. These data could also be confirmed assessing larger public datasets. For instance, analysis of Cancer Cell Line Encyclopedia dataset 25 (http://www.broadinstitute.org/ccle/home) showed that Ewing sarcoma cell lines exhibited the lowest SPRY1 levels amongst all tumor cell lines analyzed (Supplementary Figure 1).

\section{SPRY1 induction impairs cell proliferation of Ewing sarcoma cells}

The strong down-regulation of SPRY1 by EWS-FLI1, its absence of expression in Ewing sarcoma cell lines and the finding that it acts as a negative feedback inhibitor of the RAS/MAPK/ERK cascade suggest a potential function of SPRY1 inhibition in Ewing sarcoma. To test this hypothesis, we generated three doxycycline-inducible SPRY1 Ewing sarcoma cell lines (A673/TR/SPRY1, SKES/TR/SPRY1, and SKNMC/TR/SPRY1) and subjected them to several functional assays. As shown in Figure 2A, these genetically modified Ewing cell lines express high levels of SPRY1 protein upon doxycycline stimulation, while the levels of the EWS-FLI1 oncoprotein remain unaffected. Thus, they constitute a suitable model to test the consequences of exclusive SPRY1 re-expression in Ewing sarcoma without affecting the levels of EWS-FLI1 oncoprotein.

Firstly, we studied the effect of SPRY1 induction on cell proliferation (Figures 2B-D). Induction of SPRY1 in these Ewing cell lines upon doxycycline stimulation significantly reduced their proliferation. This was observed using real-time monitoring of cell number (xCELLigence instrument, ACEA Biosciences) (Figure 2B) as well as by

bromodeoxyuridine (BrdU) incorporation assays (Figures 2C and 2D). Notably, no effect on cell proliferation was observed in cells carrying the empty vector, both in absence and in presence of doxycycline (data not shown). Cell proliferation inhibition was observed in standard culture media supplemented with 10\% FBS (Figures 2B and 2C), as well as in low-serum (1\% FBS) conditions (Figure 


\section{repisälud}

2D). Induction of SPRY1 in cells grown in lowserum conditions exhibited an even stronger reduction of cell proliferation (Figure 2D), probably suggesting that in conditions where there is a diminished availability of growth factors, such as in the tumor microenvironment, SPRY1 is able to markedly impair cell proliferation.

Similarly, induction of SPRY1 expression reduced clonogenic growth of the three Ewing sarcoma cell lines plated at very low density in medium supplemented with 5\% FBS whereas cells carrying the empty vector remained unaffected upon doxycycline treatment (Figure 3A, Supplementary Figure 2A). When cells were tested for anchorage-independent growth in soft agar, no significant differences were observed in the number of colonies formed, whereas there was a significant difference in the size of the individual colonies (Figure 3B). No significant differences in anchorageindependent growth were observed in cells transfected with the empty vector when treated accordingly (Supplementary Figure 2B).

Finally, the three Ewing cell lines harboring the SPRY1 construct where cultured in presence or absence of doxycycline and assayed for cell cycle in non-synchronized cells by flow cytometry. As shown in Supplementary Figure S3, the impairment in cell proliferation in SPRY1-re-expressing cells seems partially due to a cell cycle arrest in the G1 phase, although these results were not statistically significant.

Taken together, these results provide evidence that SPRY1 induction impairs cell proliferation as well as clonogenic and anchorage-independent growth of Ewing sarcoma cell lines.

\section{SPRY1 induction impairs migration of Ewing sarcoma cells}

We next analyzed the effect of SPRY1 induction in Ewing sarcoma cells on cell migration.

As shown in Figure 3C, SPRY1 induction reduced the ability of A673, SKES, and SKNMC Ewing sarcoma cells to close an artificial wound produced in a confluent cell monolayer (in vitro wound healing assay). In addition, SPRY1 re-expression significantly impaired migration of Ewing sarcoma cells through a porous membrane (transwell assay) (Figure 3D). No differences in the migratory properties were observed in cells carrying the empty vector (data not shown). 


\section{repisälud}

\section{SPRY1 repression is necessary for ERK activation and proliferation in Ewing}

sarcoma cells.

SPRY1 has been described to inhibit MAPK/ERK pathway, which is one of the most relevant proliferative pathways in cancer. For that reason we investigated the effect of SPRY1 induction on ERK activation mediated by serum. As shown in Figure 4, SPRY1 induction reduced the levels of phospho-ERK both in low (1\%) and standard (10\%) serum conditions. Next, we explored the effect of SPRY1 induction on the ERK activation mediated by bFGF, an established and potent RASactivating growth factor. Using bFGFstimulation we observed a similar effect on ERK activation (Figure 4) in the three Ewing

cell lines.

Collectively, these results indicate that EWS-FLI1-mediated SPRY1 repression in Ewing sarcoma cells contributes to the activation of MAPK/ERK pathway, and thus to the malignant features observed.

\section{FGFR-inhibitors mimic the effects of SPRY1 re-expression.}

Since SPRY1 proved to be capable of inhibiting ERK phosphorylation, especially when the

FGF pathway was activated, we assessed the effect of 4 FGFR-inhibitors (PD-173074 [PD74], PD166866 [PD-66], SU5402 [SU54] and NVP-BGJ398 [BG-98]) on Ewing sarcoma cells (A673, SKNMC, SKES, RDES and POE) in order to test whether FGFR-inhibition can mimic SPRY1 effect on Ewing cell lines. Complementarly to our previous finding that bFGF can induce proliferation in Ewing sarcoma cell lines (i.e. A673, SKNMC and POE cells) ${ }^{26}$, we observed that FGFR-inhibition reduces proliferation of these Ewing sarcoma cells (Figure 5A) whereas it did not affect normal cells such as fibroblasts (IMR90). Consistently, FGFR-inhibition through any of the 4 FGF-inhibitors severely impairs clonogenic growth of A673, SKNMC and POE Ewing sarcoma cell lines (Figure 5B).

Since POE cells exhibited high sensitivity toward this FGFR inhibiton compared to the other cells tested (Supplementary Table 2), we chose this cell line to perform in vivo experiments to test whether PD-74 has an antitumoral effect in a xenograft model in mice. As shown in Figure 5C, PD74 treatment significantly inhibited tumor growth $(P=0.004)$ of Ewing sarcoma xenografts. These tumors showed an about 50\% decrease in the number of mitoses $(P=0.001)$ along with a $40 \%$ 


\section{repisäarlud}

increase in the number of apoptotic cells per highpower field $(P=0.001)$ when comparing vehicle vs. PD-74 treatment. Moreover, Ki-67 staining for proliferation showed a significant reduction in the number of Ki67-positive cells in the tumor samples treated with PD-74 $(P<0.01)$ (Figure 5D).

To confirm if PD-74 had an antitumoral effect in other Ewing sarcoma cell lines we performed an in vivo experiment using SKES cells, which presented less sensitivity to it in vitro (Figure 5A). As shown in Supplementary Figure S4A, PD-74 had a dose-dependent effect on SKES xenograft growth in mice, with $20 \mathrm{mg} / \mathrm{kg}$ being the most effective dose $(P=0.005)$. Again we observed a significant reduction of the number of mitoses $(P=0.01)$ and a significant increase in the number of apoptotic cells per high-power field $(P<0.001)$ upon treatment with PD-74 $(20 \mathrm{mg} / \mathrm{kg})$ (Supplementary Figure S4B). Similarly, we detected significantly less Ki-67 positive cells upon treatment of with PD-74 $(P<0.01)$ (Supplementary Figure S4B).

We next explored the combined effect of FGFR-inhibition and SPRY1 re-expression. SPRY1 was reexpressed in the three Ewing sarcoma cell lines and they were concomitantly treated with either bFGF or PD-74 alone or a combination of both (Figure 6). In analogy to the results presented in Figure 2, SPRY1 significantly inhibited cell proliferation induced by bFGF in the three cell lines studied. Moreover, the effect of SPRY1 re-expression and PD-74 on cell proliferation was similar in A673 and SKNMC cells (Figure 6). Furthermore, when the three cell lines were treated with other FGFinhibitors (BG98, PD-66 and SU54) two of them (BG98 and PD-66) were able to significantly further reduce the proliferation beyond the effect of SPRY1 alone (Supplementary Figure S5). However, when SPRY1 was re-expressed concomitantly with any of the three new inhibitors tested, none of them produced a further impairment in proliferation on any of the cells tested, which is in agreement with what was previously observed with PD-74 (Supplementary Figure S5). 


\section{repisäalud}

\section{SPRY1 expression positively correlates with improved overall survival of Ewing sarcoma}

patients.

Our results indicate that SPRY1 repression leads to a constitutive activation of MAPK/ERK pathway in response to external stimuli such as bFGF. Thus, we wondered if the expression levels of SPRY1 in situ could be associated with clinical outcome in Ewing sarcoma patients.

First, SPRY1 mRNA levels were examined in a cohort of 117 Ewing sarcoma samples studied with gene expression microarrays and compared them to published microarray datasets comprising 24 different solid tumor types ${ }^{27}$. This analysis revealed that Ewing sarcoma range among the ones with the lowest SPRY1 expression (Figure 7A), although in in situ tumors there was more heterogeneity in the SPRY1 mRNA levels as compared to Ewing sarcoma cells in culture (Figures 7B). Moreover, there was statistically less $S P R Y 1$ expression in Ewing sarcoma cell lines as compared to primary tumors. In fact, all cell lines except for one exhibited less $S P R Y I$ expression than the median sample of primary tumors. In contrast, there was no statistical difference in LOX, NROB1 and CD99 expression in cell lines when compared to primary tumors (Figure 7B).

Then, we analyzed the correlation between SPRY1 levels in primary tumors and clinical outcome in a cohort of 162 Ewing sarcoma patients ${ }^{28}$. The median expression value of SPRY1 was used as a cutoff to define moderate and low SPRY1 expression levels. Using this cut-off, moderate SPRY1 expression levels were significantly associated with a better overall survival (5-year overall survival 0.70 vs $0.38, P=0.002$; log-rank test) and event free survival (5-year event free survival 0.72 vs 0.45 , $P=0.0015$; log-rank test) (Figures 7C and D). Interestingly, low SPRY1 levels were associated with a higher risk for the presence of metastases at diagnosis ( $P=0.002$, Fisher's exact test) (Figure 6E). Collectively, these results strongly support a relationship between the levels of SPRY1 and Ewing sarcoma aggressiveness. 


\section{repisälud}

\section{DISCUSSION}

EWS-ETS fusion proteins play a central role in the pathogenesis of Ewing sarcoma by regulating the expression of other key players. In this sense, the identification of these regulated genes may help characterize the pathways involved in Ewing sarcoma pathogenesis and aggressiveness and to therefore open new opportunities for targeted

therapies ${ }^{29}$.

In this study, we showed that SPRY1, a member of the Sprouty family of proteins, is repressed by EWS-FLI1 and is not expressed in established Ewing sarcoma cell lines. The exact mechanism through which EWS-FLI1 regulates SPRY1 is still unknown. However, analysis of two independent ChIP-Seq studies ${ }^{30,31}$ indicates that EWS-FLI1 does not bind to SPRY1 promoter directly (Supplementary Figure S6). Interestingly, upon EWS-FLI1 knockdown there is an increase of H3K27ac marks located at the putative SPRY1 promoter comprising SPRY1 exon 1 and intron 1 (Supplementary Figure S6). This suggests an epigenetic mechanism of SPRY1-regulation involving histone modifications, instead of a direct binding of EWS-FLI1 to the SPRY1 promoter. Moreover, there were no significant difference in the percentage of SPRY1 CpG islands' methylation upon modulation of EWS-FLI1 expression levels ${ }^{32}$. Accordingly, we propose that the actual mechanism underlying SPRY1 regulation in Ewing sarcoma may be different from the one operating in other tumors where SPRY1 downregulation is associated with promoter methylation $22,33,34$.

Since SPRY1 has been shown to be a potent negative regulator of the RAS/MAPK/ERK signaling pathway ${ }^{35}$, we hypothesized that $S P R Y 1$ may act as a tumor suppressor gene in

Ewing sarcoma. In support of this notion, induction of SPRY1 in three independent Ewing sarcoma cell lines significantly impaired cell proliferation and migration. This is consistent with a tumor supressor function of SPRY1 in Ewing sarcoma and in agreement with previous reports showing that SPRY1 overexpression impairs cell growth, proliferation, migration and invasion of a variety of cancer cell lines including ovarian carcinoma, breast 


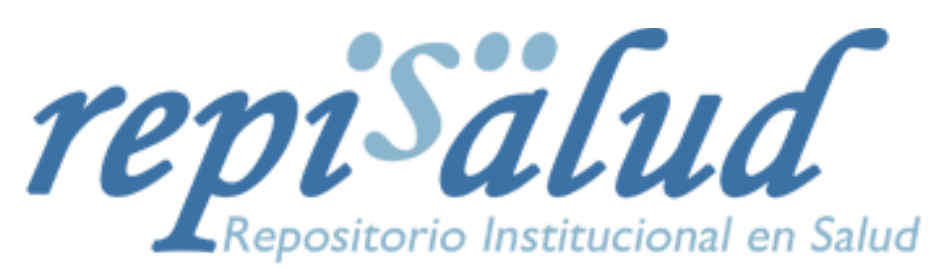

cancer, lung adenocarcinoma, colon carcinoma or osteosarcoma $24,36-38$.

Our results also demonstrate that SPRY1 downregulation is necessary for bFGF-mediated proliferation and activation of RAS/MAPK/ERK pathways in Ewing sarcoma cells. Thus, SPRY1 reexpression in the three Ewing sarcoma cell lines used in this study impaired cell proliferation and ERK phosphorylation induced by bFGF. bFGF is known to mediate proliferation, migration and differentiation in various cellular contexts ${ }^{39-42}$ and FGFregulated pathways play a preponderant role in cancer (reviewed in ${ }^{43}$ ). Notably, an important role for FGF-dependent pathways in Ewing sarcoma pathogenesis is emerging. We have recently reported that bFGF increases proliferation of Ewing sarcoma cells in vitro and that $E G R 2$, which is a downstream component of the FGF pathway, is an EWSFLI1 induced target gene ${ }^{26}$. Other studies have demonstrated that bFGF regulates motility and invasion of Ewing sarcoma cells in the bone microenvironment ${ }^{44}$. In agreement, Agelopoulos et al. recently showed that constitutive knockdown of FGFRl abolishes engraftment of Ewing sarcoma xenografts in mice ${ }^{45}$. Interestingly, over $75 \%$ of Ewing sarcoma biopsy samples present moderateto-high levels of FGFR1 phosphorylation ${ }^{44}$, although activating FGFR1 mutations are extremely rare in this disease ${ }^{45}$.

In light of these facts and our new results, we propose that constitutive activation of FGFRs and downstream pathways are key contributors to the pathogenesis of Ewing sarcoma and that EWSFLI1-mediated suppression of the negative-feedback regulator SPRY1 constitutes a major mechanism for sustained FGFR-phosphorylation and thus unrestrained FGF-induced signal transduction and tumor progression. In synopsis, our results support that SPRY1 downregulation is pre-requisite for enhanced proliferation and migration of Ewing sarcoma cells induced by either EWS-FLI1 itself, external growth factor stimulation, or a combination of both as part of an autocrine loop.

The importance of this pathway in Ewing sarcoma pathogenesis is additionally illustrated by FGFRinhibition-mediated impairment of cell proliferation and clonogenic growth of Ewing sarcoma cells in vitro. Interestingly, the search for more efficient and specific FGFR inhibitors is an active field in the pharmaceutical industry, since FGF signaling pathways is one of the most commonly mutated systems in cancer ${ }^{43}$. In this regard, the Ewing sarcoma research community can take advantage of the development of these new drugs, some of which are being tested in clinical trials with promising results, particularly in tumors harboring aberrant FGFR signaling (reviewed in ${ }^{43}$ ).

FGFR signaling can be aberrantly activated in Ewing sarcoma either through downregulation of SPRY1 (as observed in most cases), through overexpression of FGFRs (as observed in subset of patients ${ }^{45}$ ) or, very rarely through somatic mutations ${ }^{45}$. For that reason, we anticipate that Ewing sarcoma patients may benefit from targeted drugs directed against FGFRs or its downstream targets. 


\section{repisälud}

In support of this notion, Agelopoulus et al. reported on a single patient affected by relapsed Ewing sarcoma, who was treated with an FGFR-tyrosine kinase inhibitor (ponatinib), which led to a reduction in 18-FDG-PET activity and thus glucose uptake by the tumor ${ }^{45}$.

Interestingly, although SPRY1 was undetectable in established Ewing sarcoma cell lines, its levels in primary tumors were variable. Currently, the reasons for the differences between SPRY1 levels in established cell lines and tumors in situ are still unknown but it can be hypothesized that SPRY1 levels remain variable in tumors, and that the harsh conditions of in vitro cell culture favor the growth of cells with lower SPRY1 levels during establishment of Ewing sarcoma cell lines. In fact, established Ewing sarcoma cell lines harbor a much higher rate of STAG2, TP53 and CDKN1A mutations than the observed in primary tumors specimens ${ }^{46}$, suggesting that cells derived from more aggressive tumors are favored in culture 4748 .

Ewing sarcoma is a very aggressive pediatric malignancy in which primary metastasis is the most unfavorable risk factor, very often leading to fatal outcome despite highly intense and toxic treatment ${ }^{49}$. Here, we show that low SPRY1 expression levels correlate with a significantly worse overall and event-free survival in a large cohort of Ewing sarcoma patients. More interestingly, primary tumors displaying low levels of SPRY1 were more frequently observed in patients harboring metastasis at diagnosis. This is compatible with a more aggressive behavior of SPRY1-low tumors and in agreement with the results observed in the in vitro experiments. We speculate that tumors expressing low levels of SPRY1 would present a higher response to external growth factor stimulation, and thus exhibit higher rates of proliferation and migration, making them more aggressive. This may have a potential clinical application since SPRY1 has been recently proposed as a possible tissue biomarker to differentiate aggressive from indolent prostate carcinomas ${ }^{50}$.

In summary, our data provide evidence that EWS-FLI1-mediated SPRY1 downregulation is an important mechanism in Ewing sarcoma pathogenesis. Moreover, our results strongly suggest that bFGF-mediated stimulation of cell proliferation could be more important than initially acknowledged in Ewing sarcoma and that FGFR inhibitors may constitute promising drugs for treatment of Ewing sarcoma patients.

\section{MATERIAL AND METHODS}

\section{Cell culture}

A673/TR/shEF cells, which have been described elsewhere ${ }^{7}$ were cultured in Dulbecco's modified Eagle's medium (DMEM) supplemented with 10\% tetracycline-free fetal bovine serum (FBS, 


\section{repisälud}

Clontech, Mountain View, CA), $2 \mathrm{mM}$ L-glutamine, $100 \mu \mathrm{g} / \mathrm{ml}$ zeocin and $3 \mu \mathrm{g} / \mathrm{ml}$ blasticidin. Induction of a small hairpin RNA (shRNA) against EWS-FLI1 was started by the addition of $1 \mu \mathrm{g} / \mathrm{ml}$ doxycycline (Sigma, St Louis, MO). Ewing sarcoma cell lines A4573, TC-71, RD-ES, POE, TTC-466 and the normal fibroblast cell line IMR90 were maintained in RPMI 1640 medium; SK-PN-DW and SKNMC wildtype cells in

Iscove's modified Dulbecco's medium; wildtype A673 and SKES cells in DMEM. All media were supplemented, if not otherwise stated, with 10\% FBS, 2 mM L-glutamine (Invitrogen, Paisley, UK) and $1 \%$ penicillin and streptomycin. All cells were routinely tested for mycoplasma contamination (Mycoalert mycoplasma detection kit, Lonza \# LT07318) and were authenticated by STR profiling at the Genomic Facility at Biomedical Research Institute, CSIC, Madrid, Spain).

\section{Establishment of Ewing sarcoma cell lines stably expressing doxycycline-inducible}

\section{SPRY1 CDNA}

The complete coding region of SPRY1 was RT-PCR-amplified from A673/TR/shEF cells

stimulated with doxycycline using primers 5'GCGGTCGACGAGATCACTACACATGGATCC-3' (forward) and $5^{\prime}$ -

CGGCGGCCGCTCATCATCATGATGGTTTACCCTGACC-3' (reverse); The amplified fragments were digested with Sall and Notl, cloned into the pENTR2B plasmid

(Invitrogen) and transferred by recombination to the lentiviral doxycycline-inducible plasmid pLenti4-TO-V5-DEST (Invitrogen). Then, A673/TR, SKES/TR and SKNMC/TR Ewing sarcoma cells expressing the tetracycline repressor constitutively were infected with lentiviruses containing the SPRY1 cDNA. Control cells were infected with empty lentiviral vector. Stable clones were selected with zeocin $(100 \mu \mathrm{g} / \mathrm{ml})$. Induction of SPRY1 was assayed by western blots upon doxycycline (1 $\mu \mathrm{g} / \mathrm{ml}$ ) stimulation. Clones displaying the highest levels of protein expression upon doxycycline stimulation were chosen for additional studies.

\section{Reverse transcription-quantitative polymerase chain reaction (RT-qPCR)}

RT-qPCR conditions, primer and TaqMan probe sequences specific for EWS-FLI1, LOX, $N R O B 1(D A X 1)$ and TBP were described elsewhere ${ }^{7,13,51}$. TaqMan probes for SPRY1, 2, 3 and 4 were purchased to Life Technologies (San Diego, California, USA). Reactions were run on a RotorGene 6000 (Corbett Research, Sydney, Australia) and relative expression was calculated as previously described $^{51}$. 


\section{repisälud}

\section{Western blot analysis and antibodies}

Procedure was described elsewhere ${ }^{13}$. Primary antibodies were purchased to the following companies: anti-FLI1 polyclonal antibody from NeoMarkers (\# RB-9295-P) (Fremont, CA), anti-SPRY1 monoclonal antibody from Santa Cruz Biotechnology (\#100861) (Texas, USA), Tubulin monoclonal antibody from Sigma Aldrich (\#T9026) (St. Louis, MO, USA), anti-Phospho-p44/42 (pERK, \#9106) and anti-p44/42 (totalERK, \# 9102) were from Cell Signaling (Danvers, MA, USA). Anti-mouse (\# 2055) and anti-rabbit IgG (\# 2054) horseradish peroxidase-conjugated secondary antibodies were purchased from Santa Cruz Biotechnology.

\section{BrdU proliferation assay}

Cells were plated in octaplicates $\left(1 \times 10^{3}\right.$ cells per well in 96 multi-well plates) and cultured in presence or absence of doxycycline $(1 \mu \mathrm{g} / \mathrm{ml})$ for $72 \mathrm{~h}$ in $10 \%$ or $1 \%$ tetracycline-free

FBS (Clontech, Mountain View, CA, USA). Thereafter, BrdU chemiluminescent assay

(Roche, Basel, Switzerland) was performed according to manufacturer's instructions.

Chemiluminescence was measured using an Infinite M200 (Tecan, Mannerdorf,

Switzerland) microplate reader.

\section{Resazurin proliferation assay}

Cells were plated in octaplicates $\left(2.5 \times 10^{3}\right.$ cells per well in 96 multi-well plates) and concomitantly cultured in presence or absence of doxycycline $(1 \mu \mathrm{g} / \mathrm{ml})$ and stimuli $(1 \%$ or $10 \%$ tetracycline-free FBS or $10 \mathrm{ng} / \mathrm{ml} \mathrm{bFGF)} \mathrm{for} 72$ hours. For bFGF-inhibitor testing, cells were grown at $10 \%$ FBS for 72 hours in presence of PD-173074 (PD-74)

(Selleckchem, Houston, TX, USA), PD-166866 (PD-66) (\#PZ0114, Sigma Aldrich),

SU5402 (SU54) (\#S7667, Selleckchem, Houston, TX, USA) or NVP-BGJ398 (BG-98)

(\#S2183, Selleckchem, Houston, TX, USA). Thereafter, Resazurin (\#R7017, Sigma Aldrich) was added to the media at $0.15 \mu \mathrm{g} / \mathrm{ml}$ and incubated for 2 hours at $37^{\circ} \mathrm{C}$. Fluorescence was recorded using a $560 \mathrm{~nm}$ excitation/590 $\mathrm{nm}$ emission filter set in an

Infinite M200 microplate reader (Tecan). 


\section{repisälud}

\section{xCELLigence proliferation assay}

Cell proliferation was assayed in real-time with a bioelectric XCELLigence instrument (Roche/ACEA

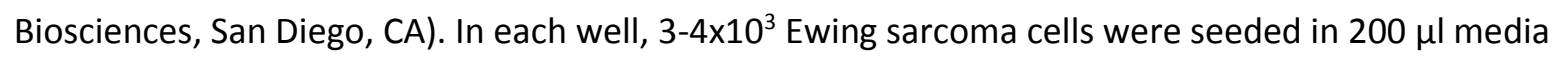
containing $10 \%$ tetracycline-free FBS and treated with doxycycline $(1 \mu \mathrm{g} / \mathrm{ml})$ or vehicle (triplicate wells/group). Cellular impedance was measured periodically and media with or without doxycycline were changed once after $72 \mathrm{~h}$.

\section{Flow cytometry analysis of cell cycle}

Cells were treated with doxycycline $(1 \mu \mathrm{g} / \mathrm{ml})$ for $72 \mathrm{~h}$ to induce the expression of SPRY 1 and fixed with $70 \%$ ethanol for 24 hours at $4 \stackrel{\circ}{\circ}$. Then they were stained with a solution of $0.005 \%(w / v)$ of propidium iodide (PI) and RNAase A as recommended by the manufacturer (BD biosciences, San José, CA, USA) and were incubated at 37 oC for 30 minutes. They were then analyzed in a MACS Quant Analyzer flow cytometer (Miltenyi

Biotec, Cologne, Germany).

\section{Wound healing assay}

Cells were plated in triplicates $\left(2-4 \times 10^{4}\right.$ cells per well in 24 multi-well plates) and were incubated with or without doxycycline $(1 \mu \mathrm{g} / \mathrm{ml})$ for $72 \mathrm{~h}$ prior to the assay. At the end of this period, a "wound gap" in the cell monolayer was created using a micropipette tip. The healing of the gap by cell migrating was monitored by photographing the progress every 6 to $12 \mathrm{~h}$ until wound closure. Quantification of relative cell migration is described elsewhere

52.

\section{Transwell assay}

Cells were pre-treated with doxycycline $(1 \mu \mathrm{g} / \mathrm{ml})$ for $24 \mathrm{~h}$ to induce the expression of SPRY1 protein. Then, they were starved $(0.5 \%$ fetal bovine serum) for another additional 24 hours in the same doxycycline conditions. Then, $3 \times 10^{5}$ pre-treated cells were resuspended in $2 \mathrm{ml}$ of medium containing $0.5 \%$ tetracycline-free FBS and placed in the upper chamber of transwells $(8.0 \mu \mathrm{m}$ pore size) (Corning Costar, Cambridge, MA, USA) following the procedure described elsewhere ${ }^{13}$. 


\section{repisälud}

\section{Soft agar assays}

Cells were plated by triplicate $\left(5 \times 10^{5}\right.$ cells per $60 \mathrm{~mm}$ dishes) in soft agar and cultured in presence or absence of doxycycline during 25 days. Fresh culture medium was added to plates every 2-3 days. At the end of the experiment, three random fields for each plate were photographed. The number of colonies per field and its respective area were calculated using NIH ImageJ software.

\section{Clonogenic assay}

A673/TR/SPRY1, SKES/TR/SPRY1 and SKNMC/TR/SPRY1 cells were plated in

triplicates at $0.5 \times 10^{3}, 1 \times 10^{3}$ and $2 \times 10^{3}$ cells per well respectively in a 24 -well plate. They were subsequently treated with or without doxycycline $(1 \mu \mathrm{g} / \mathrm{ml})$ and maintained for 9 days in culture media supplemented with $5 \%$ tetracycline-free FBS. Media was changed every 34 days and doxycycline treatment was continued. Finally, colonies were fixed, stained with crystal violet and photographed. Cells were de-stained using $50 \%$ ethanol $0.1 \mathrm{M}$ sodium citrate; pH 4.2. Absorbance was quantified at $560 \mathrm{~nm}$ using an Infinite M200 (Tecan) microplate reader.

\section{Tumor xenografts in mice}

POE and SKES cells were resuspended in PBS/matrigel (BD Biosciences, Le Pont de Claix Cedex, France) $(1: 1)$ and injected $\left(8 \times 10^{6} / 200 \mu l\right)$ subcutaneously in the flanks of six-week old C.B17/SCID male and female mice (Charles Rivers Laboratories, France). When tumor volume reached $150 \mathrm{~mm}^{3}$ (calculated with the formula length $\times$ width $\times$ depth $\times 0.5432$ ), mice were injected intraperitoneally once a day with the indicated dose of PD-173074 $(5,10$ or

$20 \mathrm{mg} / \mathrm{kg}$ ) dissolved in 10\% DMSO-90\% Corn Oil (Sigma) or placebo in the control group. Tumor growth was monitored with a caliper and mice were sacrificed when tumors reached a volume of $1500 \mathrm{~mm}^{3}$. Experiments were carried out in accordance with recommendations of the European Community (86/609/EEC), the French Competent Authority, the

UKCCCR guidelines (guidelines for the welfare and use of animals in cancer research), the Ethics Committee at ISCIII (CBA \#64_2015-v2) and the Spanish Competent Authority (PROEX 009/16).

\section{Histology and immunohistochemistry (IHC)}




\section{repisälud}

IHC analyses were done on formalin-fixed, paraffin-embedded xenograft tumors. All tissue samples were collected at the Institute of Pathology of the LMU Munich for immediate IHC staining for which 4- $\mu \mathrm{m}$ sections were cut. Antigen retrieval was carried out by microwave treatment in Dako target retrieval solution (S2369). The following primary antibodies were used: polyclonal rabbit anticleaved-caspase-3 (1:100 at room temperature for $60 \mathrm{~min}$; \#9661, Cell Signaling) or monoclonal rabbit anti-Ki67 (1:200 at room temperature for $60 \mathrm{~min}$; \#275R-15 clone SP6, Cell Marque). The ImmPRESS Reagent Kit anti-rabbit IgG (MP-7401) was used for antigen detection. Sections were counterstained with hematoxylin Gill's Formula (H-3401, Vector laboratories). The average number of positive cells was determined by analysis of 10 high-power fields (HPF, 40x magnification) for each xenograft tumor. Statistical differences between groups were calculated with an unpaired towtailed Student's T-test.

\section{Patients}

A total of 162 Ewing sarcoma patients with available clinical data and tumor samples were used in this study. This cohort consists of 117 Ewing patients for which gene expression profiles in primary tumors were analyzed with HG-U133 plus2.0 microarrays (Affymetrix, Santa Clara, CA) (GEO accession number GSE34620) and 45 patients whose gene expression profiles were studied with Uniset Human 20K I microarrays (Codelink Amersham Bioscience, Piscataway, NJ). All patients received a similar protocol treatment.

\section{Statistical analysis}

For a single comparison of two groups, two-tailed Student's t test was used and a normal distribution was assumed. Variances between the groups that were compared were similar.

For animal studies, the sample size was estimated to be $6-8$ mice considering a signal/noise

$(\mathrm{S} / \mathrm{N})$ ratio of $1.6-1.8,80 \%$ power, assuming a $5 \%$ significance level and a two-sided test. No investigator blinding was done during the experiment. For in situ studies including overall survival and relapse-free survival probabilities, log-rank test was used. For proportions, Fisher's exact test was used. For all analyses, the level of significance was set at $P=0.05$, and the variance was similar 


\section{repisälud}

between groups. All statistical calculations were performed using the GraphPad Prism software version 6.0 (GraphPad Software, San Diego,

CA, USA).

\section{CONFLICT OF INTEREST}

The authors declare no potential conflict of interest.

\section{ACKNOWLEGMENTS}

F.C-A., L.G-G., J.C.L., A.S., P.G-M., S.E.L-P., S.M., and J.A. are supported by

Asociación Pablo Ugarte and Miguelañez S.A, ASION-La Hucha de Tomás, Fundación La

Sonrisa de Alex and Instituto de Salud Carlos III (PI12/00816 and Spanish Cancer Network

RTICC RD12/0036/0027). T.G.P.G. is supported by a grant from 'Verein zur Förderung von Wissenschaft und Forschung an der Medizinischen Fakultät der LMU München

(WiFoMed)', the Daimler and Benz Foundation in cooperation with the Reinhard Frank Foundation, by LMU Munich's Institutional Strategy LMUexcellent within the framework of the German Excellence Initiative, the 'Mehr LEBEN für krebskranke Kinder - BettinaBräu-Stiftung', the Walter Schulz Foundation, the Fritz Thyssen Foundation (FTH40.15.0.030MN) and by the German Cancer Aid (DKH-111886). The "Genetics and

Biology of Cancers" team (T.G.P.G., D.S., O.D.) is supported by grants from the Ligue

Nationale Contre Le Cancer (Equipe labellisée). This work was also supported by the European PROVABES, ASSET and EEC FP7 grants. We also thank the following

associations for their invaluable support: the Société Française des Cancers de l'Enfant, Courir pour Mathieu, Dans les pas du Géant, Olivier Chape, Les Bagouzamanon, Enfants et Santé and les Amis de Claire. We thank Dr. S. Navarro (university of Valencia, Valencia,

Spain) and Dr. T.J. Triche (Children's Hospital Los Angeles, Los Angeles, USA) for provide us with Ewing sarcoma cell lines A4573 and TTC-466 respectively. 


\section{repisäalud}

\section{REFERENCES}

1 Mackintosh C, Madoz-Gurpide J, Ordonez JL, Osuna D, Herrero-Martin D. The molecular pathogenesis of Ewing's sarcoma. Cancer Biol Ther 9: 655-667.

2 Grohar PJ, Helman LJ. Prospects and challenges for the development of new therapies for Ewing sarcoma. Pharmacol Ther 137: 216-224.

3 Ladenstein R, Potschger U, Le Deley MC, Whelan J, Paulussen M, Oberlin O et al. Primary disseminated multifocal Ewing sarcoma: results of the Euro-EWING 99 trial. J Clin Oncol 28: 3284-3291. 


\section{repisälud}

4 Zhu L, McManus MM, Hughes DP. Understanding the Biology of Bone Sarcoma from Early Initiating Events through Late Events in Metastasis and Disease Progression. Front Oncol 3: 230.

5 Delattre O, Zucman J, Plougastel B, Desmaze C, Melot T, Peter M et al. Gene fusion with an ETS DNA-binding domain caused by chromosome translocation in human tumours. Nature 359: 162-165.

6 Kovar H. Blocking the road, stopping the engine or killing the driver? Advances in targeting EWS/FLI-1 fusion in Ewing sarcoma as novel therapy. Expert Opin Ther Targets 18: 13151328.

7 Carrillo J, Garcia-Aragoncillo E, Azorin D, Agra N, Sastre A, Gonzalez-Mediero I et al. Cholecystokinin down-regulation by RNA interference impairs Ewing tumor growth. Clin Cancer Res 13: 2429-2440.

8 Garcia-Aragoncillo E, Carrillo J, Lalli E, Agra N, Gomez-Lopez G, Pestana A et al. DAX1, a direct target of EWS/FLI1 oncoprotein, is a principal regulator of cellcycle progression in Ewing's tumor cells. Oncogene 27: 6034-6043.

9 Smith R, Owen LA, Trem DJ, Wong JS, Whangbo JS, Golub TR et al. Expression profiling of EWS/FLI identifies NKX2.2 as a critical target gene in Ewing's sarcoma. Cancer Cell 9: 405416. 


\section{repisälud}

10 Surdez D, Benetkiewicz M, Perrin V, Han ZY, Pierron G, Ballet S et al. Targeting the EWSR1FLI1 oncogene-induced protein kinase PKC-beta abolishes ewing sarcoma growth. Cancer Res 72: 4494-4503.

11 Grunewald TG, Diebold I, Esposito I, Plehm S, Hauer K, Thiel U et al. STEAP1 is associated with the invasive and oxidative stress phenotype of Ewing tumors. Mol Cancer Res 10: $52-$ 65.

12 Prieur A, Tirode F, Cohen P, Delattre O. EWS/FLI-1 silencing and gene profiling of Ewing cells reveal downstream oncogenic pathways and a crucial role for repression of insulin-like growth factor binding protein 3. Mol Cell Biol 24: 72757283.

13 Agra N, Cidre F, Garcia-Garcia L, de la Parra J, Alonso J. Lysyl oxidase is downregulated by the EWS/FLI1 oncoprotein and its propeptide domain displays tumor supressor activities in ewing sarcoma cells. PLoS One 8: e66281.

14 Navarro D, Agra N, Pestana A, Alonso J, Gonzalez-Sancho JM. The EWS/FLI1 oncogenic protein inhibits expression of the Wnt inhibitor DICKKOPF-1 gene and antagonizes betacatenin/TCF-mediated transcription. Carcinogenesis 31: 394-401.

15 Hahm KB, Cho K, Lee C, Im YH, Chang J, Choi SG et al. Repression of the gene encoding the TGF-beta type II receptor is a major target of the EWS-FLI1 oncoprotein. Nat Genet 23: 222227. 


\section{repisälud}

16 Minowada G, Jarvis LA, Chi CL, Neubuser A, Sun X, Hacohen N et al. Vertebrate Sprouty genes are induced by FGF signaling and can cause chondrodysplasia when overexpressed. Development 126: 4465-4475.

17 Guy GR, Wong ES, Yusoff P, Chandramouli S, Lo TL, Lim J et al. Sprouty: how does the branch manager work? J Cell Sci 116: 3061-3068.

18 Christofori G. Split personalities: the agonistic antagonist Sprouty. Nat Cell Biol 5: 377-379.

19 Zhao Z, Zuber J, Diaz-Flores E, Lintault L, Kogan SC, Shannon K et al. p53 loss promotes acute myeloid leukemia by enabling aberrant self-renewal. Genes Dev 24:

1389-1402.

20 Fritzsche S, Kenzelmann M, Hoffmann MJ, Muller M, Engers R, Grone HJ et al. Concomitant down-regulation of SPRY1 and SPRY2 in prostate carcinoma. Endocr Relat Cancer 13: 839-849.

21 Lo TL, Yusoff P, Fong CW, Guo K, McCaw BJ, Phillips WA et al. The ras/mitogen-activated protein kinase pathway inhibitor and likely tumor suppressor proteins, sprouty 1 and sprouty 2 are deregulated in breast cancer. Cancer Res 64: 6127-6136.

22 Kwabi-Addo B, Ren C, Ittmann M. DNA methylation and aberrant expression of Sprouty1 in human prostate cancer. Epigenetics 4: 54-61.

23 Kwabi-Addo B, Wang J, Erdem H, Vaid A, Castro P, Ayala G et al. The expression of Sprouty1, an inhibitor of fibroblast growth factor signal transduction, is decreased in human prostate cancer. Cancer Res 64: 4728-4735. 


\section{repisälud}

24 Masoumi-Moghaddam S, Amini A, Ehteda A, Wei AQ, Morris DL. The expression of the Sprouty 1 protein inversely correlates with growth, proliferation, migration and invasion of ovarian cancer cells. J Ovarian Res 7: 61.

25 Barretina J, Caponigro G, Stransky N, Venkatesan K, Margolin AA, Kim S et al. The Cancer Cell Line Encyclopedia enables predictive modelling of anticancer drug sensitivity. Nature 483: 603-607.

26 Grunewald TG, Bernard V, Gilardi-Hebenstreit P, Raynal V, Surdez D, Aynaud MM et al. Chimeric EWSR1-FLI1 regulates the Ewing sarcoma susceptibility gene EGR2 via a GGAA microsatellite. Nat Genet 47: 1073-1078.

27 Willier S, Butt E, Grunewald TG. Lysophosphatidic acid (LPA) signalling in cell migration and cancer invasion: a focussed review and analysis of LPA receptor gene expression on the basis of more than 1700 cancer microarrays. Biol Cell 105: 317-

333.

28 Postel-Vinay S, Veron AS, Tirode F, Pierron G, Reynaud S, Kovar H et al. Common variants near TARDBP and EGR2 are associated with susceptibility to Ewing sarcoma. Nat Genet 44: 323-327.

29 Cidre-Aranaz F, Alonso J. EWS/FLI1 Target Genes and Therapeutic Opportunities in Ewing Sarcoma. Front Oncol 5: 162.

30 Bilke S, Schwentner R, Yang F, Kauer M, Jug G, Walker RL et al. Oncogenic ETS fusions deregulate E2F3 target genes in Ewing sarcoma and prostate cancer. Genome Res 23: 17971809. 


\section{repisälud}

31 Riggi N, Knoechel B, Gillespie SM, Rheinbay E, Boulay G, Suva ML et al. EWSFLI1 utilizes divergent chromatin remodeling mechanisms to directly activate or repress enhancer elements in Ewing sarcoma. Cancer Cell 26: 668-681.

32 Tomazou EM, Sheffield NC, Schmidl C, Schuster M, Schonegger A, Datlinger P et al. Epigenome mapping reveals distinct modes of gene regulation and widespread enhancer reprogramming by the oncogenic fusion protein EWS-FLI1. Cell Rep 10: 1082-1095.

33 Calvisi DF, Ladu S, Gorden A, Farina M, Lee JS, Conner EA et al. Mechanistic and prognostic significance of aberrant methylation in the molecular pathogenesis of human hepatocellular carcinoma. J Clin Invest 117: 2713-2722.

34 Macia A, Gallel P, Vaquero M, Gou-Fabregas M, Santacana M, Maliszewska A et al. Sprouty1 is a candidate tumor-suppressor gene in medullary thyroid carcinoma.

Oncogene 31: 3961-3972.

35 Gross I, Bassit B, Benezra M, Licht JD. Mammalian sprouty proteins inhibit cell growth and differentiation by preventing ras activation. J Biol Chem 276: 4646046468.

36 Mekkawy AH, Pourgholami MH, Morris DL. Human Sprouty1 suppresses growth, migration, and invasion in human breast cancer cells. Tumour Biol 35: 5037-5048.

37 Wiles ET, Lui-Sargent B, Bell R, Lessnick SL. BCL11B is up-regulated by EWS/FLI and contributes to the transformed phenotype in Ewing sarcoma. PLoS One 8: e59369.

38 Liu X, Lan Y, Zhang D, Wang K, Wang Y, Hua ZC. SPRY1 promotes the 


\section{repisälud}

degradation of UPAR and inhibits UPAR-mediated cell adhesion and proliferation. Am J Cancer Res 4: 683-697.

39 Powers CJ, McLeskey SW, Wellstein A. Fibroblast growth factors, their receptors and signaling. Endocr Relat Cancer 7: 165-197.

40 Bottcher RT, Niehrs C. Fibroblast growth factor signaling during early vertebrate development. Endocr Rev 26: 63-77.

41 Chalkiadaki G, Nikitovic D, Berdiaki A, Sifaki M, Krasagakis K, Katonis $P$ et al. Fibroblast growth factor-2 modulates melanoma adhesion and migration through a syndecan-4dependent mechanism. Int J Biochem Cell Biol 41: 1323-1331.

42 Yamaguchi F, Saya H, Bruner JM, Morrison RS. Differential expression of two fibroblast growth factor-receptor genes is associated with malignant progression in human astrocytomas. Proc Natl Acad Sci U S A 91: 484-488.

43 Touat M, Ileana E, Postel-Vinay S, Andre F, Soria JC. Targeting FGFR Signaling in Cancer. Clin Cancer Res 21: 2684-2694.

44 Kamura S, Matsumoto Y, Fukushi JI, Fujiwara T, lida K, Okada Y et al. Basic fibroblast growth factor in the bone microenvironment enhances cell motility and invasion of Ewing's sarcoma family of tumours by activating the FGFR1-PI3KRac1 pathway. Br J Cancer 103: 370-381.

45 Agelopoulos K, Richter GH, Schmidt E, Dirksen U, von Heyking K, Moser B et al.

Deep Sequencing in Conjunction with Expression and Functional Analyses Reveals Activation of FGFR1 in Ewing Sarcoma. Clin Cancer Res 2015; e-pub ahead of print 2015/07/17; doi:10.1158/1078-0432.ccr-14-2744. 


\section{repisälud}

46 Tirode F, Surdez D, Ma X, Parker M, Le Deley MC, Bahrami A et al. Genomic landscape of Ewing sarcoma defines an aggressive subtype with co-association of STAG2 and TP53 mutations. Cancer Discov 4: 1342-1353.

47 Kovar H, Jug G, Aryee DN, Zoubek A, Ambros P, Gruber B et al. Among genes involved in the RB dependent cell cycle regulatory cascade, the p16 tumor suppressor gene is frequently lost in the Ewing family of tumors. Oncogene 15: 2225-2232.

48 Kovar H, Pospisilova S, Jug G, Printz D, Gadner H. Response of Ewing tumor cells to forced and activated p53 expression. Oncogene 22: 3193-3204.

49 Gaspar N, Hawkins DS, Dirksen U, Lewis IJ, Ferrari S, Le Deley MC et al. Ewing Sarcoma: Current Management and Future Approaches Through Collaboration. J Clin Oncol 33: 3036-3046.

50 Terada N, Shiraishi T, Zeng Y, Aw-Yong KM, Liu Z, Takahashi S et al. Correlation of Sprouty1 and Jagged1 with Aggressive Prostate Cancer Cells with Different Sensitivities to Androgen Deprivation. J Cell Biochem 2014; e-pub ahead of print; doi:10.1002/jcb.24805http://www.ncbi.nlm.nih.gov/pubmed/24604720.

51 Mendiola M, Carrillo J, Garcia E, Lalli E, Hernandez T, de Alava E et al. The orphan nuclear receptor DAX1 is up-regulated by the EWS/FLI1 oncoprotein and is highly expressed in Ewing tumors. Int J Cancer 118: 1381-1389.

52 Yue PY, Leung EP, Mak NK, Wong RN. A simplified method for quantifying cell migration/wound healing in 96-well plates. J Biomol Screen 15: 427-433. 


\section{repisäarlud}

\section{FIGURE LEGENDS}

Figure 1. SPRY1 is negatively regulated by EWS-FLI1 oncoprotein.

A. Time course of SPRY1, 2, 3 and 4 upon EWS-FLI1 doxycycline-inducible knockdown in A673/TR/shEF. EWS-FLI1 expression and two known target genes like LOX and NROB1 were included as controls. mRNA levels were quantified by real time RTqPCR, normalized to that of $T B P$ (reference gene) and referred to unstimulated cells. Figure shows data of one out of three independent experiments done in triplicate with equivalent results. EWS-FLII inhibition in A673/TR/shEF cells selectively upregulates

SPRY1 more than 1,000 times over the rest of members of the SPRY family of genes.

As expected, LOX appears upregulated ${ }^{13}$ and NROBI downregulated ${ }^{51}$ upon EWSFLI1 knockdown. 


\section{repisälud}

B. SPRY1 protein is re-expressed upon EWS-FLI1 knockdown in A673/TR/shEF cells. SPRY1 protein is undetectable by western blot in A673 cells grown in the absence of doxycycline and thus expressing EWS-FLI1. Incubation of A673/TR/shEWSFLI1 cells with doxycycline $(1 \mu \mathrm{g} / \mathrm{ml}, 72$ hours) inhibits EWS-FLI1 expression and dramatically induces re-expression of SPRY1 protein. Tubulin was used as a control for loading and transferring.

C. SPRY1 is undetectable at protein level by western blot in 8 Ewing sarcoma cell lines. Expression of the different EWS-ETS proteins is also shown. Tubulin was used as a control for loading and transferring.

D. SPRY1, 2, 3 and 4 mRNA levels in Ewing sarcoma cell lines. Box plot shows absence of SPRY1 expression in all Ewing sarcoma cell lines tested relative to other members of the SPRY family. The figure shows the expression levels normalized to that of TBP (reference gene).

\section{Figure 2. SPRY1 re-expression impairs proliferation in Ewing sarcoma cell lines.}

A. A673/TR, SKES/TR and SKNMC/TR Ewing cell lines expressing constitutively the tetracycline repressor (TR) were infected with a doxycycline-inducible lentiviral vector encoding the SPRY1 cDNA. The figure shows the expression of SPRY1 protein in whole protein extracts isolated from A673/TR/SPRY1 (clone 1), SKES/TR/SPRY1

(clone 7) and SKNMC/TR/SPRY1 (clone 2) cells stimulated with doxycycline (DOX, $1 \mu \mathrm{g} / \mathrm{ml}, 72$ hours). High SPRY1 levels were detected in all three cell lines after doxycycline stimulation. EWSFLI1 expression was not affected by SPRY1 ectopic expression. The same blot was stripped and incubated with anti-tubulin as a control for loading and transferring.

B. Cell proliferation was assayed in A673/TR/SPRY1, SKES/TR/SPRY1 and SKNMC/TR/SPRY1 cells using an xCELLigence assay with or without re-expression of SPRY1 (DOX, $1 \mu \mathrm{g} / \mathrm{ml}$ ). Graphs 


\section{repisälud}

depict the growth curves of the cells cultured in the absence or presence of doxycycline during $120 \mathrm{~h}$ and they show one representative experiment out of three independent experiments performed. Re-expression of SPRY1 produces a significant inhibition of cell proliferation. Slight artifacts in the graphs at $72 \mathrm{~h}$ are a consequence of media change and subsequent readjustment of the conditions in the XCELLigence device and do not affect the final result.

C. A673/TR/SPRY1, SKES/TR/SPRY1 and SKNMC/TR/SPRY1 cells were plated in octuplicates and cultured in presence or absence of doxycycline (DOX, $1 \mu \mathrm{g} / \mathrm{ml}$ ) for $72 \mathrm{~h}$ in 10\% tetracycline-free fetal bovine serum supplemented media (standard culture conditions). Cell proliferation was assayed by BrdU incorporation into DNA. Graphs depict the percentage of cell proliferation of doxycycline treated cells (expressing SPRY1) versus control. Figure depicts one representative experiment (mean \pm SD) out of three independent experiments performed (*** $P<0.005)$.

D. Cells were platted and cultured as described in C, but kept in $1 \%$ fetal bovine serum supplemented media (low-serum conditions). Cell proliferation is significantly inhibited in doxycycline treated cells (expressing SPRY1) versus control. Figure depicts one representative experiment (mean \pm SD) out of three independent experiments performed (*** $P<0.005$ ).

\section{Figure 3. SPRY1 re-expression impairs Ewing sarcoma cell clonogenicity, anchorage}

independent growth, migration and invasion of Ewing sarcoma cells.

A. A673/TR/SPRY1, SKES/TR/SPRY1 and SKNMC/TR/SPRY1 cells were platted in

triplicates at low densities and treated with or without doxycycline (DOX, $1 \mu \mathrm{g} / \mathrm{ml}$ ) for 9 days. Colony formation was measured by crystal violet staining. Pictures show representative wells of one out of three independent experiments. Graphs depict a quantification of absorbance measured after cell de-staining (one representative experiment out of 3 performed) (mean \pm $\mathrm{SD})$. Clonogenic growth is significantly impaired in all three cell lines upon SPRY1 re-expression (* $P<0.05$, ** $P<0.01$, *** $P<0.005)$.

B. A673/TR/SPRY1, SKES/TR/SPRY1 and SKNMC/TR/SPRY1 cells were platted in triplicate in soft agar and cultured in presence or absence of doxycycline (DOX, $1 \mu \mathrm{g} / \mathrm{ml}$ ) during 25 days and 


\section{repisälud}

subsequently stained with crystal violet. Pictures show representative images of sphere formation taken at the end of the experiment. Graphs depict the mean area per particle after 25 days (mean \pm SD). SPRY1 re-expression inhibits sphere formation in all three cell lines (3 independent experiments) $\left(* P<0.05,{ }^{* *} P<0.01,{ }^{* * *} P<0.005\right)$.

C. A673/TR/SPRY1, SKES/TR/SPRY1 and SKNMC/TR/SPRY1 cells were platted in triplicates and treated with or without doxycycline (DOX, $1 \mu \mathrm{g} / \mathrm{ml}$ ) for $72 \mathrm{~h}$. A "wound gap" was created by scratching the cell monolayer using a micropipette tip. Pictures depict the healing of the gap as a consequence of cell migration at the beginning, middle and end of the experiments. Relative wound closure for each cell line at the end of the experiment is stated in percentages. Images show a representative experiment out of three performed.

D. A673/TR/SPRY1, SKES/TR/SPRY1 and SKNMC/TR/SPRY1 cells were incubated in absence or presence of doxycycline (DOX, $1 \mu \mathrm{g} / \mathrm{ml}$ ) during $48 \mathrm{~h}$ to induce the expression of SPRY1 protein. Afterwards, cells were starved for another $24 \mathrm{~h}$. Then they were placed in the upper compartment of a transwell and allowed to migrate through the membrane in response to serum. Migrating cells were quantified by crystal violet staining. The figure shows the mean \pm SD of two experiments performed in triplicate. Data are shown as arbitrary units of absorbance (abs) ${ }^{*} P<0.05, * * * P<$

0.005).

Figure 4. SPRY1 inhibits MAPK pathway in Ewing sarcoma cells by inhibiting ERK phosphorylation induced by bFGF or serum.

A673/TR/SPRY1, SKES/TR/SPRY1 and SKNMC/TR/SPRY1 cells were incubated in the absence or in the presence of doxycycline (DOX, $1 \mu \mathrm{g} / \mathrm{ml}$ ) during $48 \mathrm{~h}$ to induce the expression of SPRY1 protein. Afterwards, cells were starved for an extra $24 \mathrm{~h}$ (1\% FBS), and finally stimulated for 15 min with $10 \%$ FBS or bFGF (bFGF: basic fibroblast growth factor) $(10 \mathrm{ng} / \mathrm{ml})$ where indicated. SPRY1, phospho-ERK (pERK), ERK and EWS-FLI1 proteins were detected by specific antibodies. Anti-tubulin was used as a control for loading and transferring. SPRY1 re-expression is capable of inhibiting ERK 


\section{repisälud}

phosphorylation induced by bFGF or serum in all three cell lines. Graphs depict densitometries corresponding to the western blot bands showing $\mathrm{pERK/total} \mathrm{ERK} \mathrm{ratios} \mathrm{in} \mathrm{percentage} \mathrm{versus} \mathrm{cells}$ cultured in absence of doxycycline (control). The figure shows one representative experiment out of 3 performed.

\section{Figure 5. FGFR-inhibitors block Ewing cell lines proliferation}

A. Four FGFR-inhibitors, namely PD-173074 (PD-74), PD-166866 (PD-66), SU5402

(SU54) and NVP-BGJ398 (BG-98), inhibit A673, SKNMC, POE, RDES and SKES Ewing cells growth in vitro in a dose-dependent manner whereas normal cells (IMR90 fibroblasts) remained unaffected. PD-74 proved to be most effective in 4 out of 5 Ewing sarcoma cell lines tested. Cells were grown in $10 \%$ FBS conditions and cell proliferation was measured after $72 \mathrm{~h}$ using a Resazurin assay.

B. PD-173074 (PD-74), PD-166866 (PD-66), SU5402 (SU54) and NVP-BGJ398 (BG-98) impair A673, SKNMC and POE Ewing sarcoma cells clonogenic growth in vitro when cells are grown at $5 \% \mathrm{FBS}$ for 10-12 days.

C. C.B17/SCID mice were injected with POE cells and randomly split in groups. Each group was treated intraperitoneally once a day with PD-74 or placebo. The figure shows the evolution of tumor volume (mean \pm SEM of 6-8 animals per group) versus time. PD-74 treatment significantly inhibits tumor growth $(P=0.004)$ of Ewing sarcoma xenografts.

D. Immunohistochemistry images of tumors obtained in the in vivo experiments. Tissue sections were stained with $\mathrm{Ki}-67$ to detect proliferation and cleaved caspase 3 to detect apoptosis. The graphs show how PD-74 treatment reduces the number of mitoses $(P=0.001)$ and increases the number of apoptotic cells per field $(P=0.001)$. Ki-67 staining and graph show a reduction in the number of Ki67-positive $(++$ or + ) cells when treated with PD-74 $(P<0.01)$. 


\section{repisälud}

Figure 6. bFGF induces proliferation of Ewing sarcoma cells, which can be antagonized by FGFR-inhibition.

A673/TR/SPRY1, SKES/TR/SPRY1 and SKNMC/TR/SPRY1 cells were incubated in the absence or in the presence of doxycycline (DOX, $1 \mu \mathrm{g} / \mathrm{ml}$ ) to induce the expression of SPRY1 protein and were concomitantly cultured with 1\% FBS, bFGF (10 ng/ml), PD173074 (PD-74, $5 \mu \mathrm{M})$ or a combination of bFGF and PD-74 where indicated. Cell proliferation was measured after $72 \mathrm{~h}$ using the Resazurin assay. Graphs depict one independent experiment (mean \pm SD) out of three performed. SPRY1 reexpression and PD-74 inhibit cell proliferation induced serum or bFGF treatment $\left({ }^{*} P<0.05, * * P<\right.$ $0.005, \mathrm{~ns}=$ non-significant).

Figure 7. SPRY1 expression is positively correlated with improved overall survival of Ewing sarcoma patients.

A. SPRY1 mRNA expression levels in 24 different solid tumor entities as determined by Affymetrix HG-U133plus2.0 DNA microarrays. Data were retrieved from the Gene Expression Omnibus (GEO) or the European bioinformatics Institute (EBI) and simultaneously normalized by RMA using brain array CDF files (v17, ENTREZG) as previously described ${ }^{27}$. Data are represented as medians with boxes representing the interquartile range. Whiskers indicate the $10^{\text {th }}$ and $90^{\text {th }}$ percentile of the data. The number of analyzed samples is given in parentheses. Ewing sarcoma tumors are shown in gray. GIST: gastrointestinal stromal tumor, ATRT: atypical teratoid rhabdoid tumor, RMS: rhabdomyosarcoma, NSCLC: non-small cell lung carcinoma, Ca-: carcinoma.

B. Relative expression of $S P R Y 1$ as compared to other EWS-FLI1 target genes $(L O X, N R O B 1)$ and CD99 in 15 individual Ewing sarcoma cell lines versus 117 primary Ewing sarcoma samples (all Affymetrix HG-U133Plus2.0 microarrays). Data were retrieved from the GEO (accession codes: GSE8596, GSE36133, GSE70826, and GSE34620) and simultaneously normalized by RMA using brainarray CDF files (v17, ENTREZG) as previously described ${ }^{27}$. Unpaired two-tailed Student's Ttest. 


\section{repisälud}

C. Kaplan-Meier survival estimates (overall survival) in the Ewing sarcoma patient cohort. Patients were classified as being either SPRY1-low or -moderate (cut-off: median SPRY1 expression; $P=$ 0.002, log-rank test).

D. Graph depicts the relapse-free survival probability versus SPRY1 level of expression (low or moderate, cut-off: median SPRY1 expression). SPRY1 expression positively correlates with improved relapse-free probability $(P=0.0015$, log rank test).

E. Graph shows the percentage of cases with metastasis at diagnosis versus SPRY1 level of expression (low or moderate, cut-off: median SPRY1 expression). Moderate SPRY1 expression correlates with lower risk of metastasis at diagnosis ( $P=0.002$, Fisher's exact test). 


\section{repisälud}

\section{FIGURE 1}

Cidre-Aranaz et al.
A

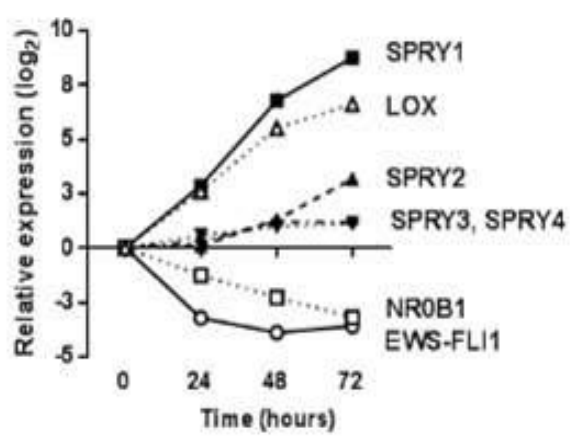

D

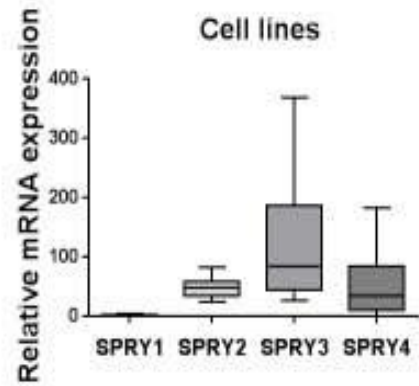

B C

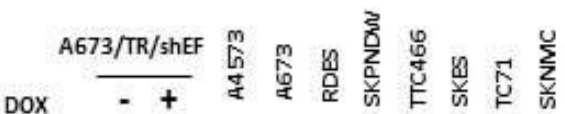

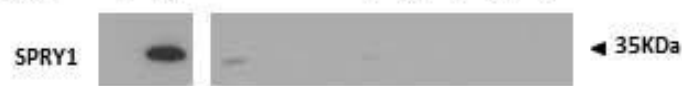

EWS-Fu1

Tubulin
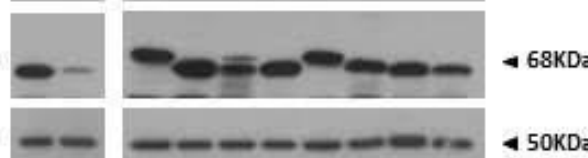

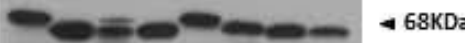

$-2-1-2-2 \mathrm{kn}+50 \mathrm{KDa}$ 
FIGURE 2

Cidre-Aranaz et al.

A

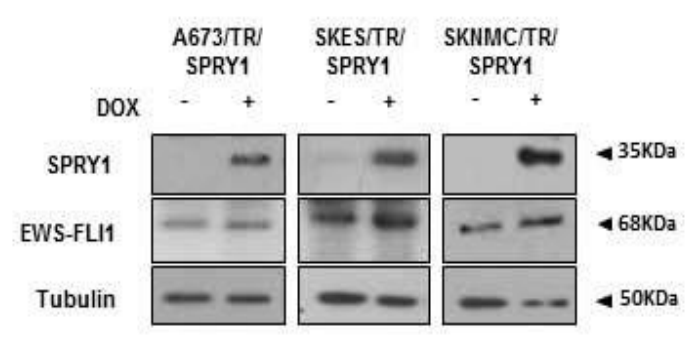

C Cell proliferation-BrdU incorporation (10\% FBS)
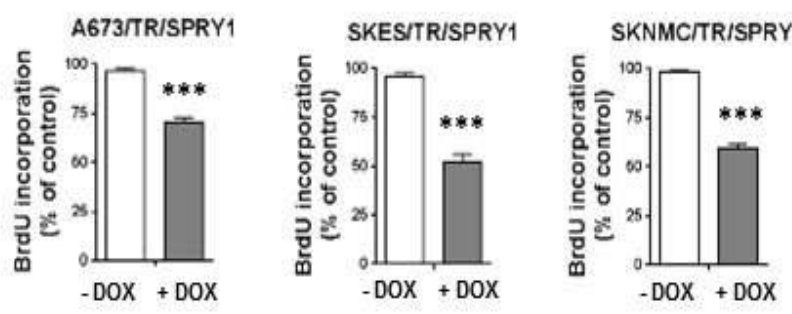

B Cell proliferation-xCELLigence( $10 \% \mathrm{FBS})$

$-\cdot \operatorname{DOX}$

A673/TRISPRY1
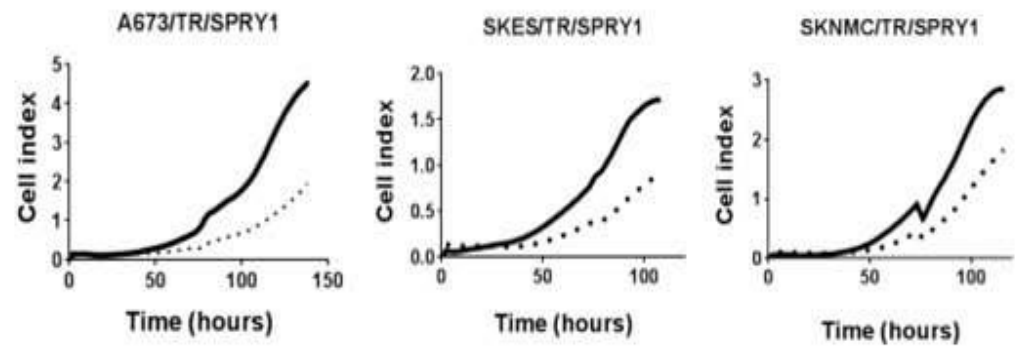

D Cell proliferation-BrdU incorporation ( $1 \%$ FBS)
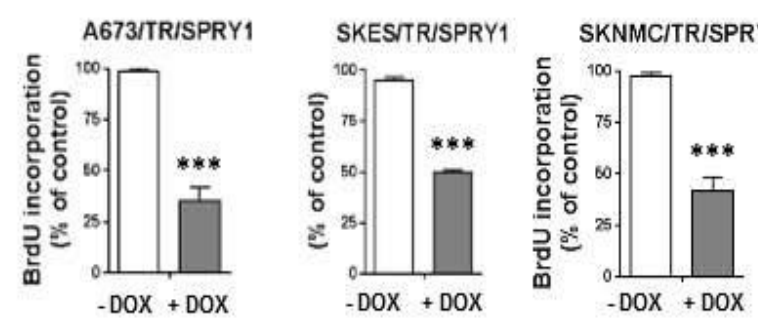
FIGURE 3

Cidre-Aranaz et al.

A Clonogenic growth assay
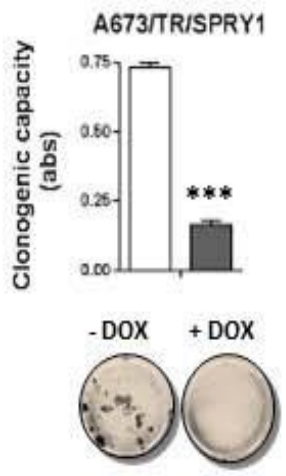
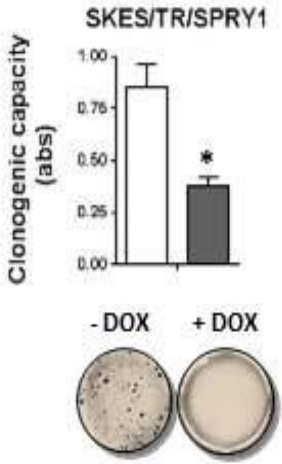
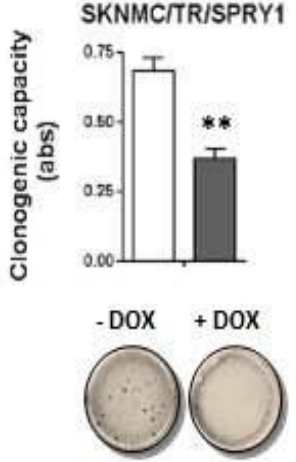

B

Anchorage-independent growth
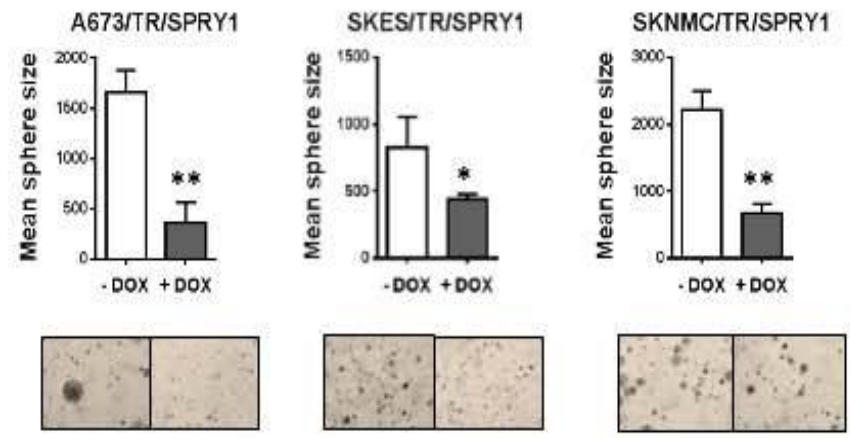

\section{Migration -In vitro wound healingassay}

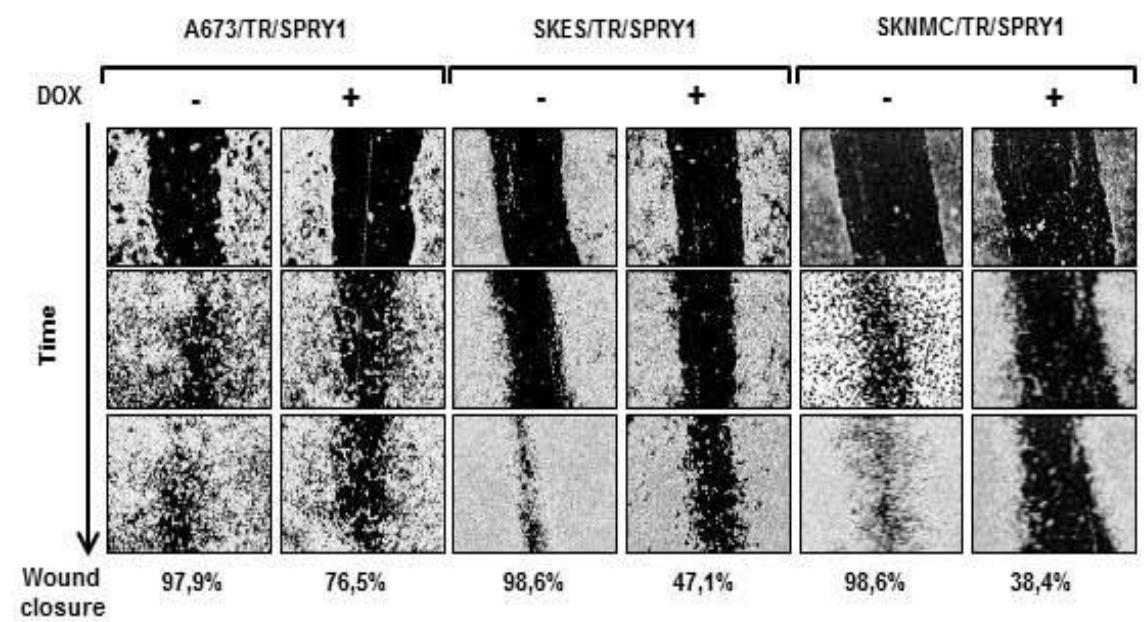

D Migration-Transwell assay
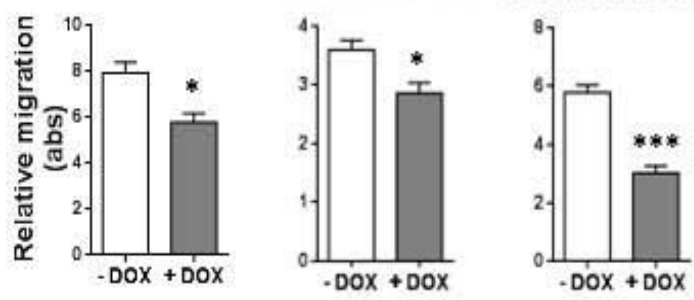
FIGURE 4

Cidre-Aranaz et al.
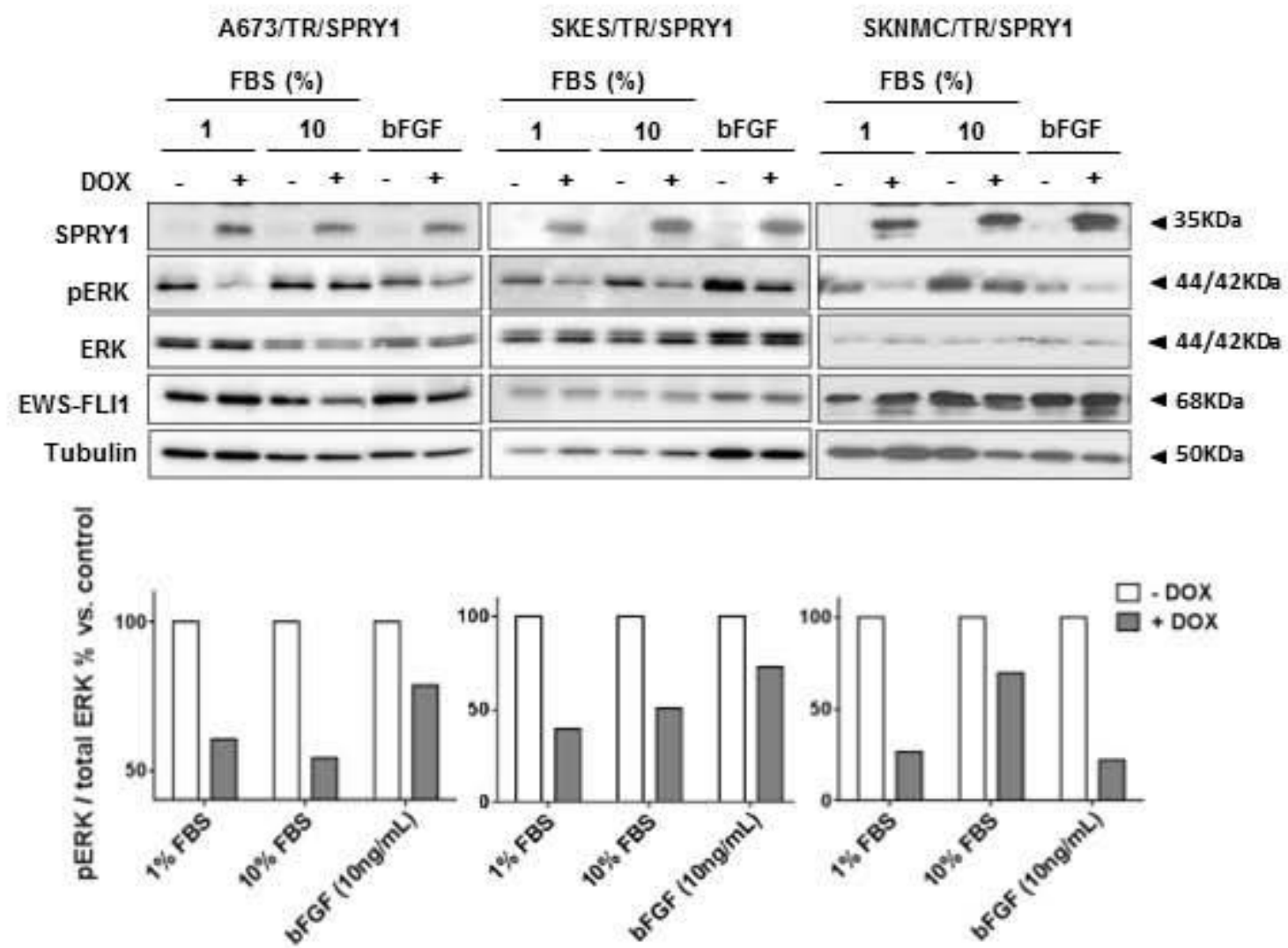


\section{FIGURE 5}

Cidre-Aranaz et al.

A Growthinhibition-Resazurinassay

0. PD-74 * PD66

- BG.98 — SU54

SKNMC

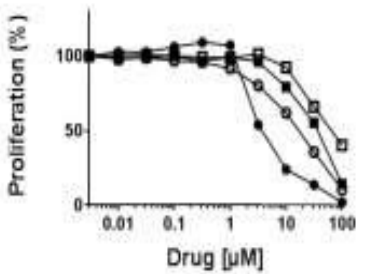

RDES

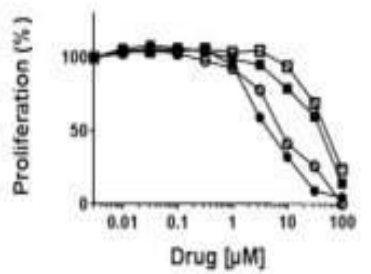

C Invivo tumorgrowth inhibition

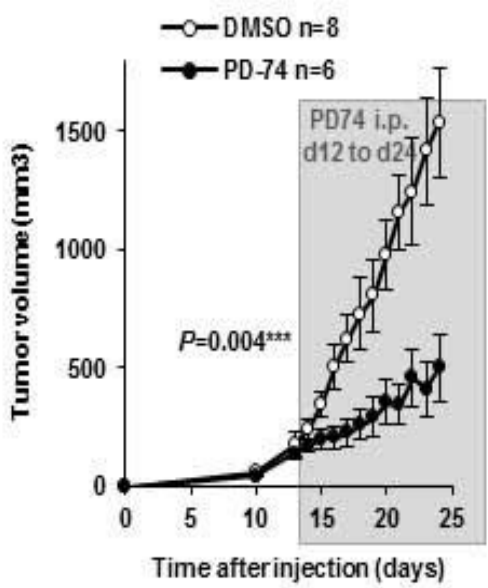

POE

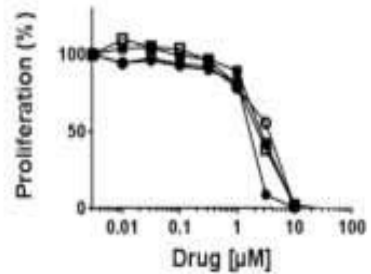

A673

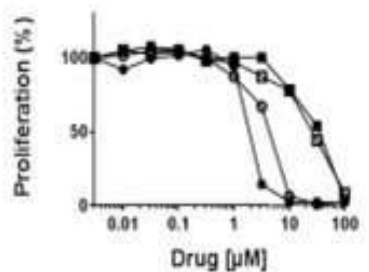

D
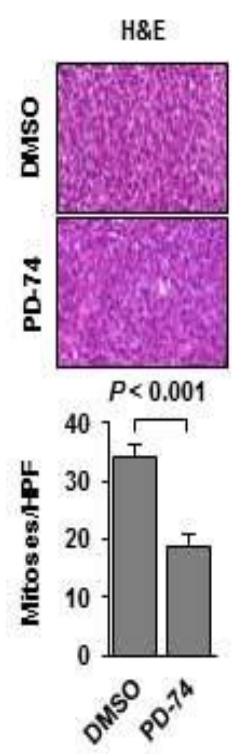

SKES

IMR90
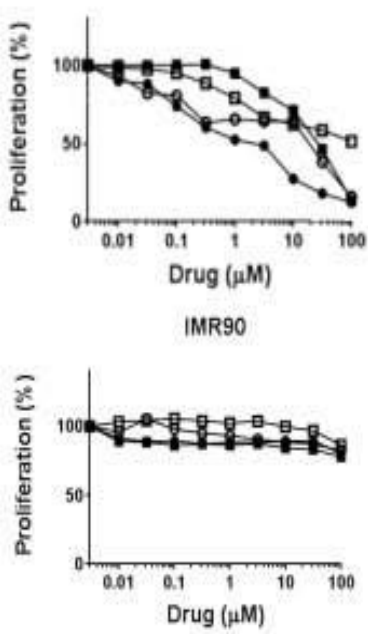

峞
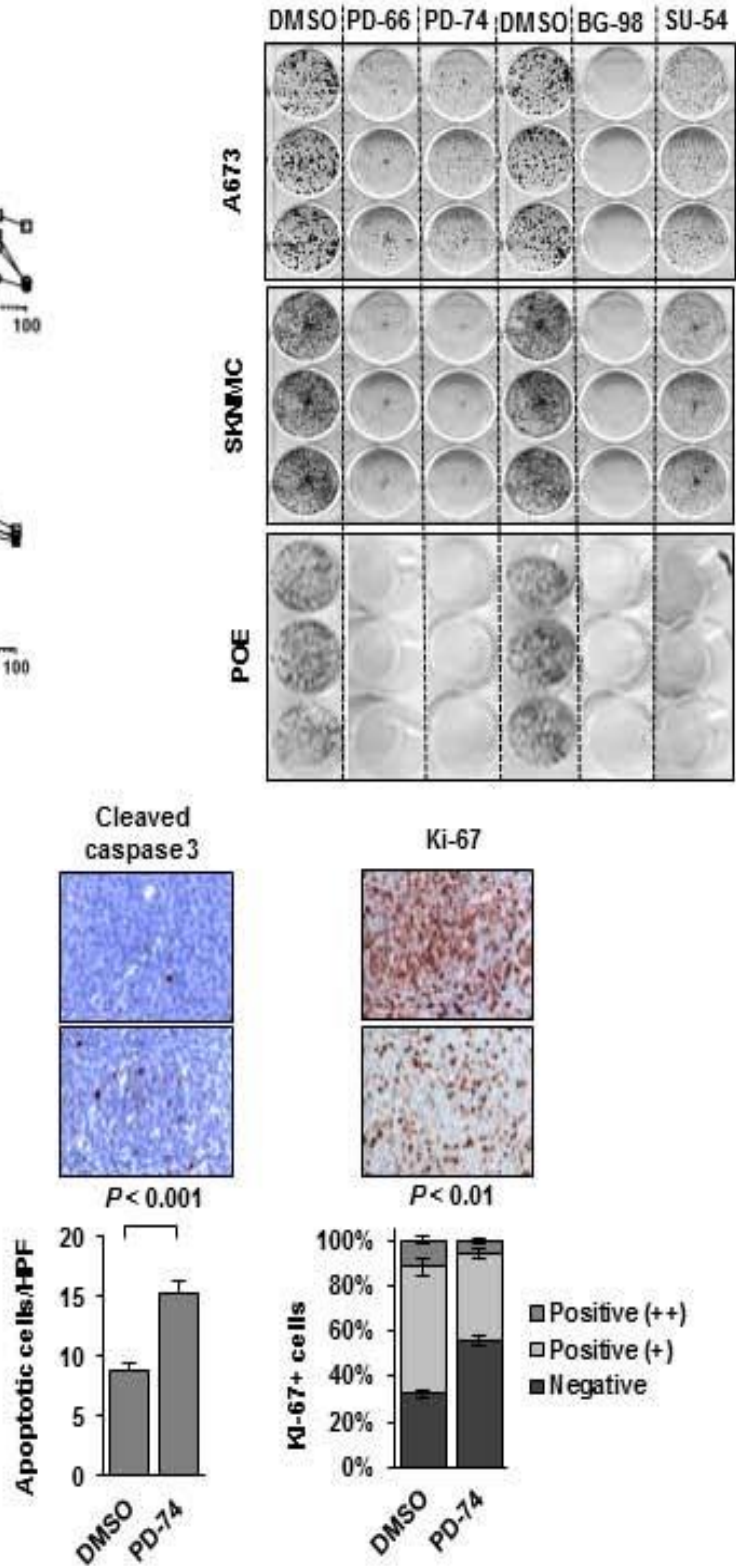

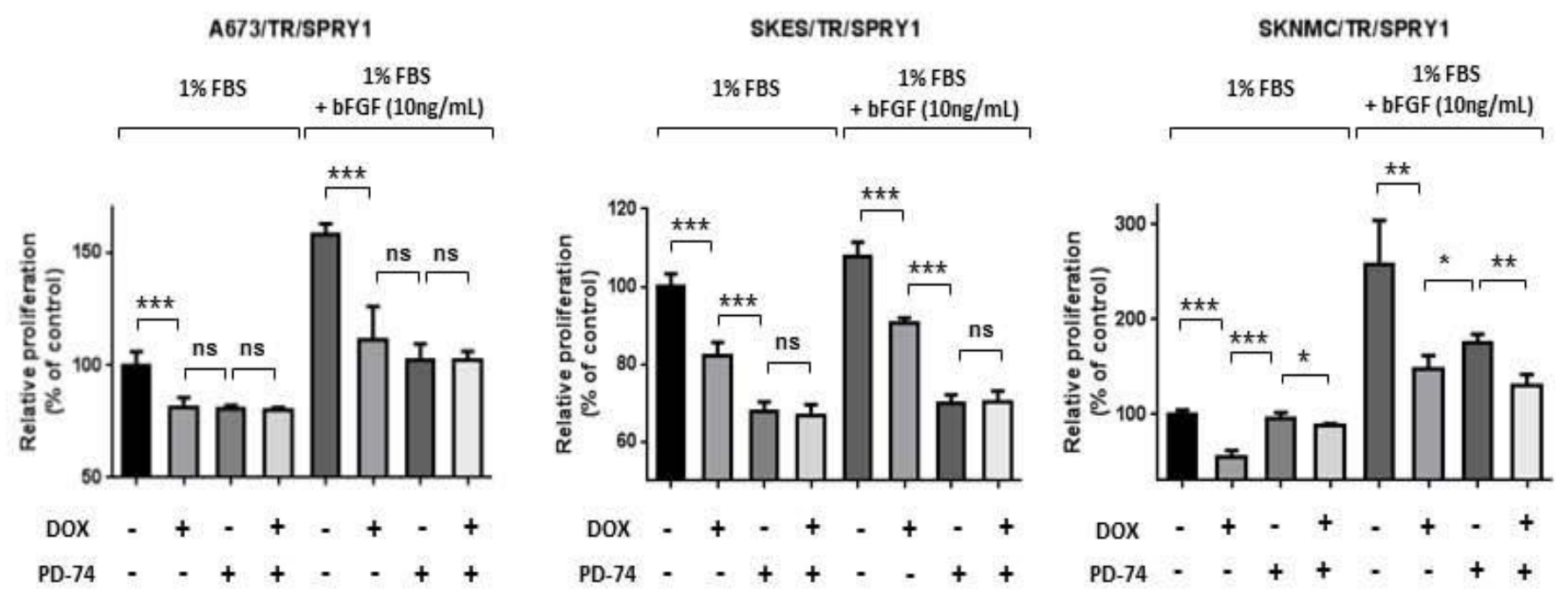
FIGURE 7

Cidre-Aranaz et al.

A

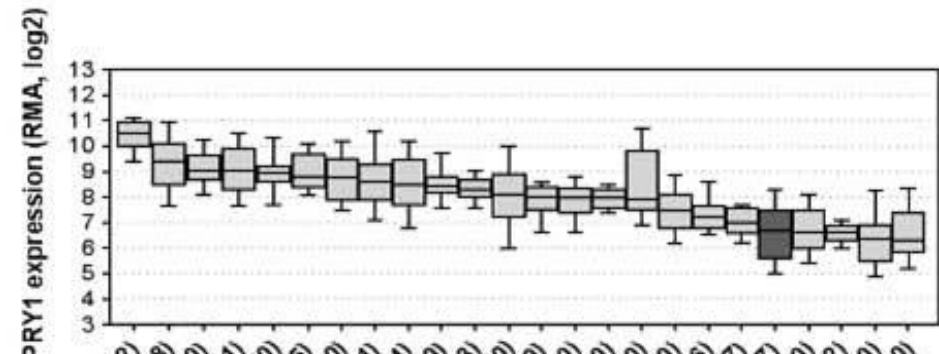

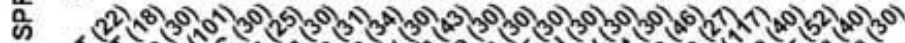

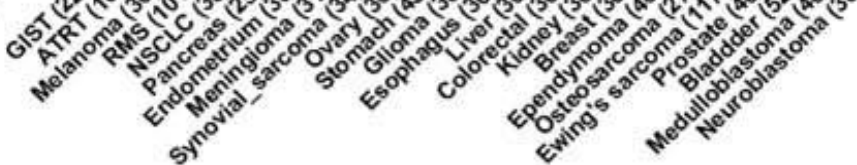

C

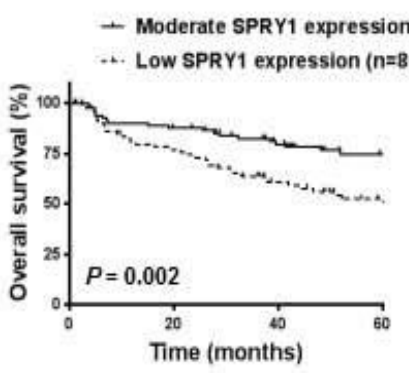

D

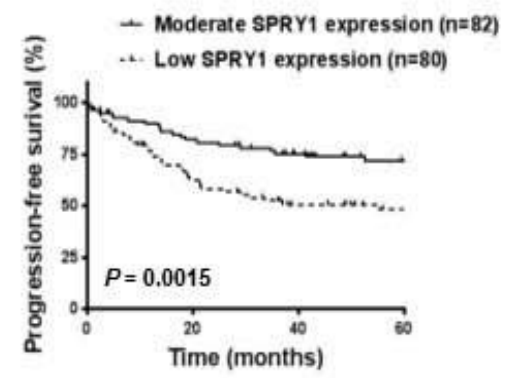

B
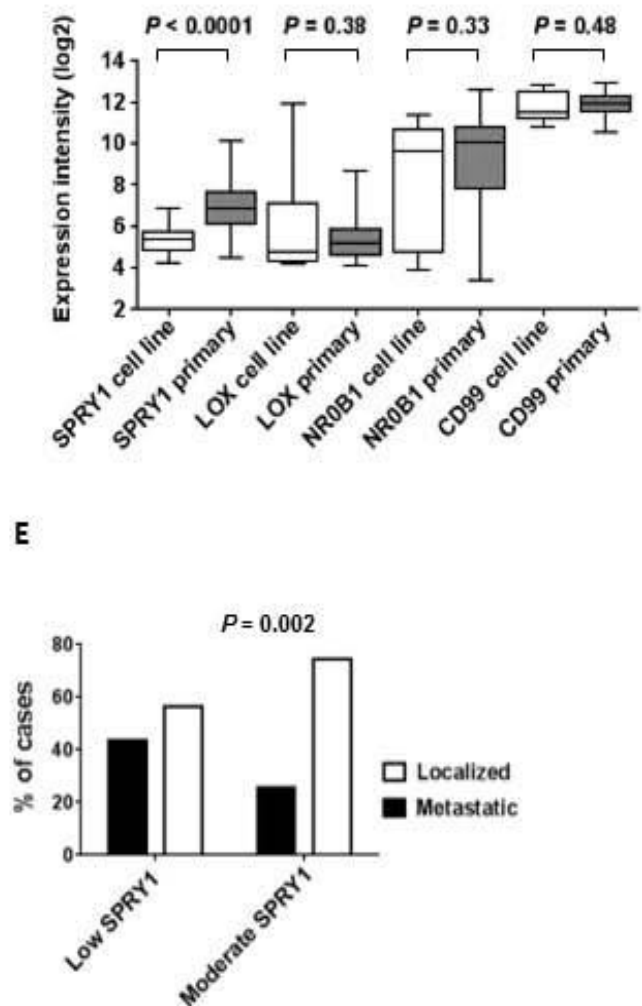
Cidre-Aranaz et al.

SUPPLEMENTARY FIGURE 1
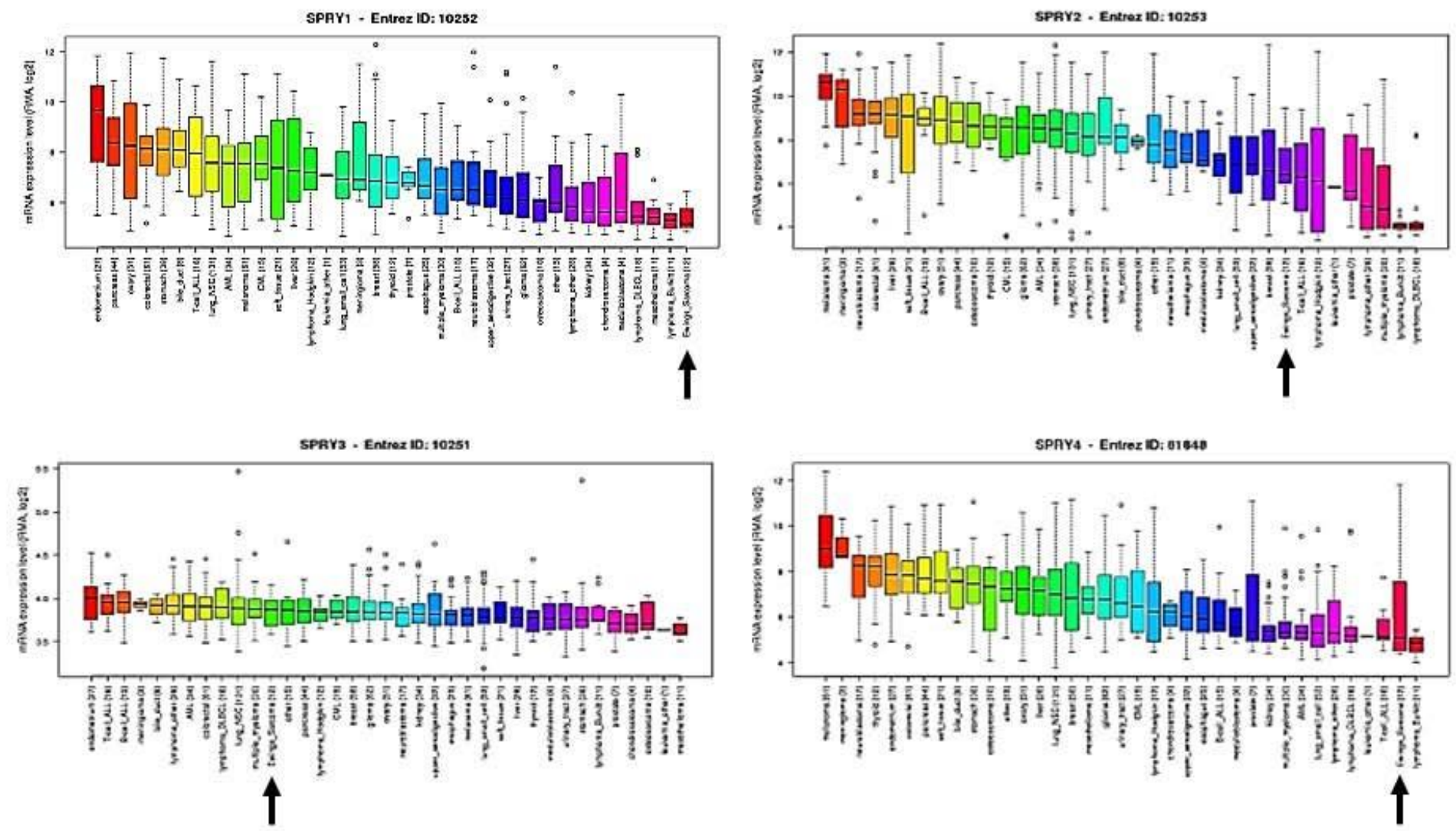

Supplementary Figure S1. Gene expression data for SPRY1, -2, -3 and -4 as determined in the Cancer Cell Line Encyclopedia (CCLE) (http://www.broadinstitute.org/ccle) (Barretina J. et al., The Cancer Cell Line Encyclopedia enables predictive modelling of anticancer drug sensitivity. Nature. 2012. 483(7391):603-7. doi: 10.1038/nature11003. 


\section{repisälud}

\section{Cidre-Aranaz et al.}

SUPPLEMENTARY FIGURE 2

A

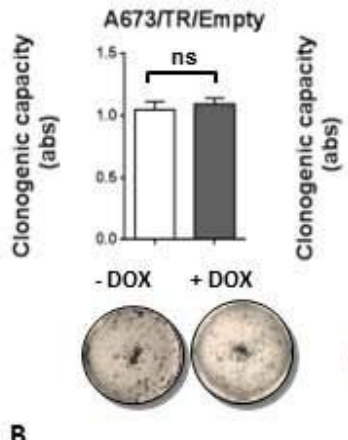

B

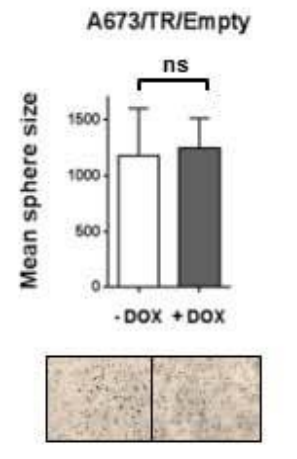

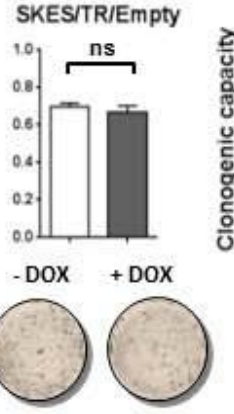

SKES/TR/Empty
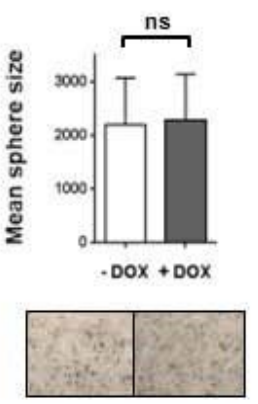

SKNMC/TRJEmpty
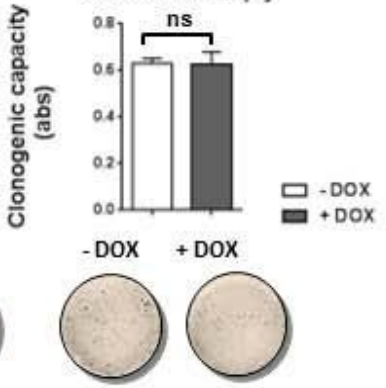

SKNMCITRJEmpty
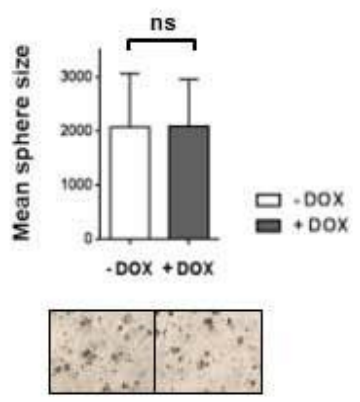

Supplementary Figure S2. Control cells carrying the empty vector do not present changes in their clonogenic capacity or anchorage-independent growth when treated with doxycycline. A. A673/TR/Empty, SKES/TR/Empty and SKNMC/TR/Empty cells were platted in triplicates at low densities and treated with or without doxycycline (DOX, $1 \mu \mathrm{g} / \mathrm{ml})$ for 9 days. Colony formation was measured by crystal violet staining. Pictures show representative wells of one out of three independent experiments. Graphs depict a quantification of absorbance measured after cell de-staining (one representative experiment out of 3 performed) (mean \pm SD). Clonogenic growth remains unaffected upon doxycycline treatment in control cells. B. A673/TR/Empty, SKES/TR/Empty and SKNMC/TR/Empty cells were platted in triplicate in soft agar and cultured in presence or absence of doxycycline (DOX, $1 \mu \mathrm{g} / \mathrm{ml}$ ) during 25 days and subsequently stained with crystal violet. Pictures show representative images of sphere formation taken at the end of the experiment. Graphs depict the mean area per particle after 25 days (mean \pm SD). Sphere formation capacity remains unaffected in all three cell lines. (ns: non significant). 

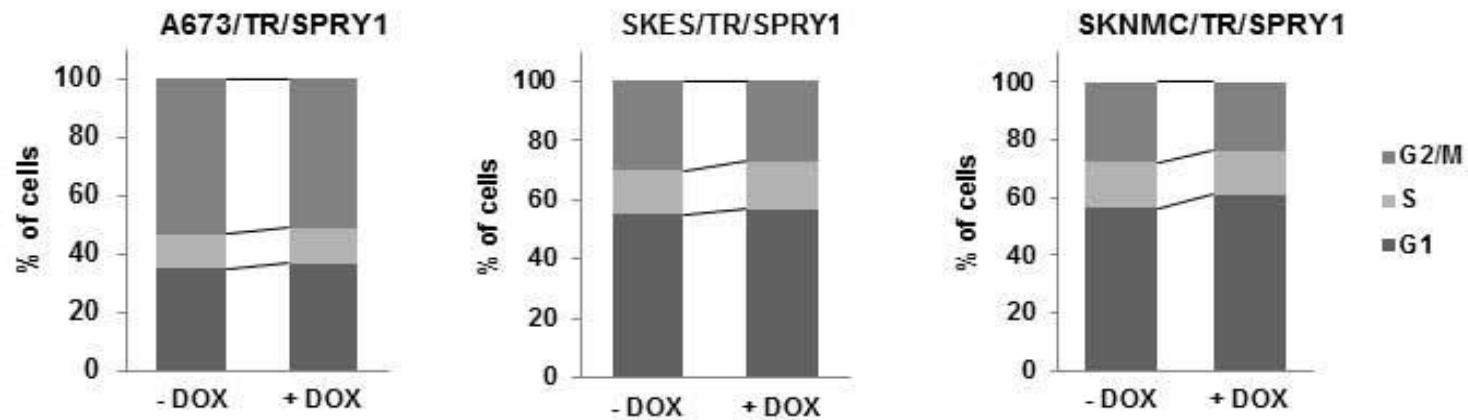

Supplementary Figure S3. The impairment in cell proliferation in SPRY1-re-expressing cells is partially due to a cell cycle arrest in phase G1. A673/TR/SPRY1, SKES/TR/SPRY1 and SKNMC/TR/SPRY1 cells treated with or without doxycycline $(-1+\mathrm{DOX} ; 1 \mu \mathrm{g} / \mathrm{ml})$ for 72 hours and stained with propidium iodide for cell cycle analysis presented a modest tendency to be arrested in phase G1 (non-significant). Graphs show one representative experiment of three performed. 
A

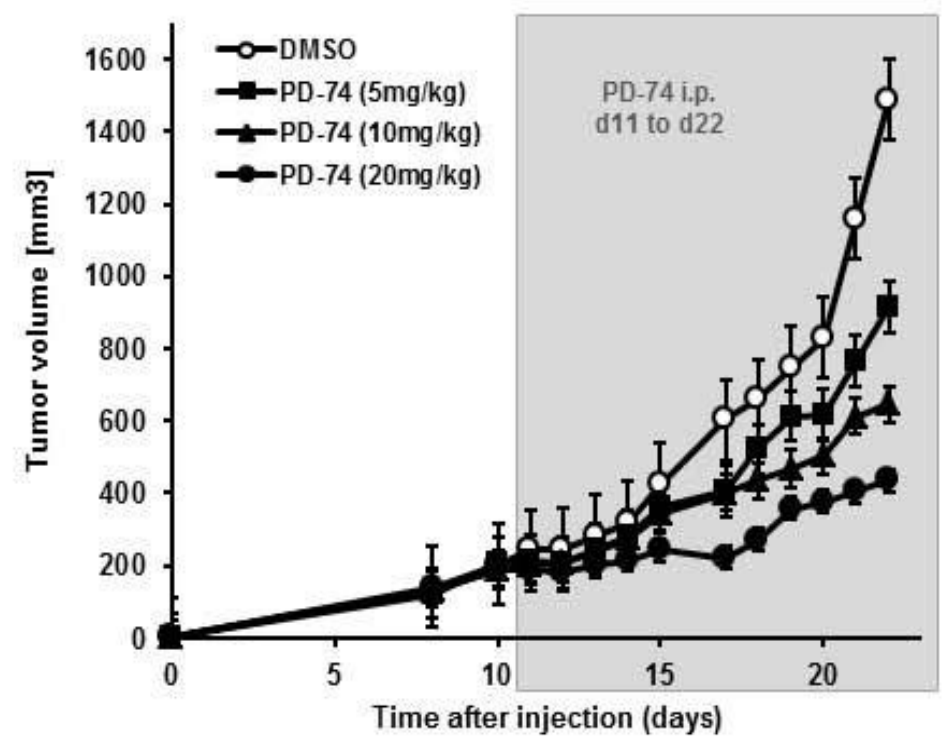

B

H\&E
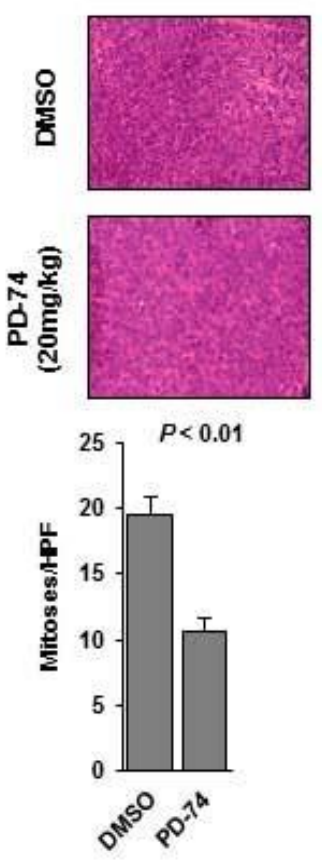

Cleaved caspase 3
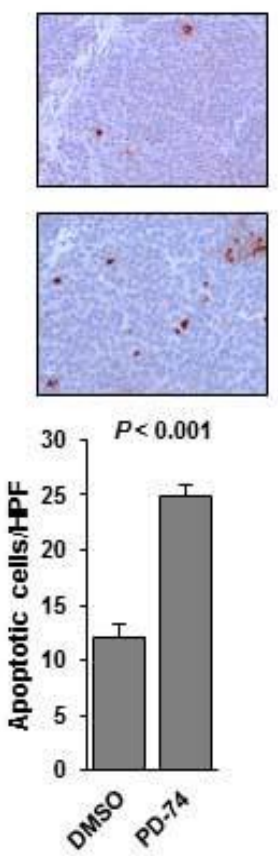

Ki-67
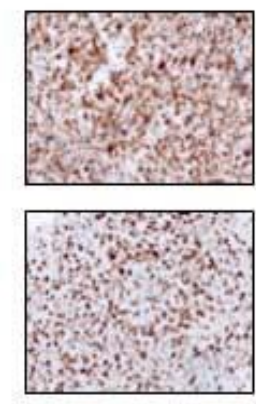

$P<0.01$

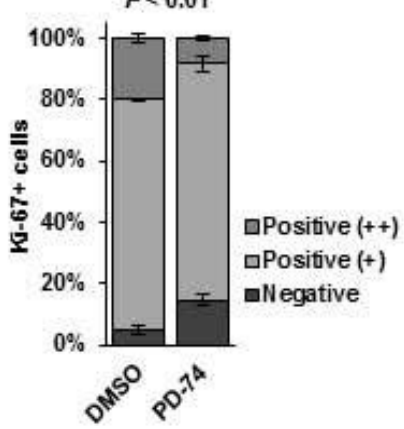

Supplementary Figure S4. The FGF-inhibitor PD-74 impairs tumor growth of Ewing sarcoma xenografts in a dose-dependent manner. A. B17/SCID mice were injected with SKES cells and randomly split in groups. Each group was treated intraperitoneally once a day with PD-74 at the doses stated or placebo (DMSO, control). The figure shows the evolution of tumor volume (mean \pm SEM of 6 animals per group) versus time. PD-74 treatment significantly inhibits tumor growth at the $20 \mathrm{mg} / \mathrm{kg}$ dose $(P=0.005)$ of Ewing sarcoma xenografts. B. Immunohistochemistry images of tumors obtained in the in vivo experiments. Tissue sections were stained for Ki-67 to detect proliferation and cleaved caspase 3 to detect apoptosis. The graphs show how PD-74 treatment $(20 \mathrm{mg} / \mathrm{kg})$ reduces the number of mitoses $(P=0.01)$ and increases the number of apoptotic cells per field $(P<0.001)$. Ki-67 staining and graph show a reduction in the number of Ki67-positive $(++$ or +$)$ cells when treated with PD-74 $(P<0.01)$. 

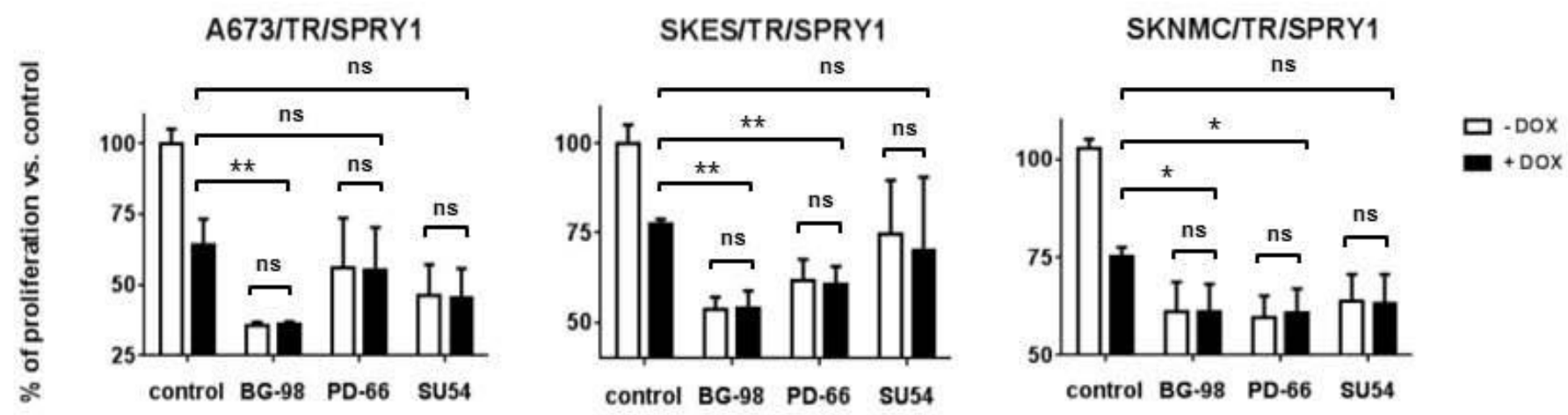

Supplementary Figure S5. FGF-inhibitors impair Ewing cell lines proliferation. A673/TR/SPRY1, SKES/TR/SPRY1 and SKNMC/TR/SPRY1 cells were treated in the presence or absence of doxycycline $(-1+$ DOX) and each inhibitor (BG-98, PD-66 and SU54 at $5 \mu \mathrm{M}$ each). SPRY1 impairs proliferation in all cases. BG-98 and PD-66 are able to significantly further reduce the proliferation in absence of doxycycline whereas the effect of SU54 is less potent. SPRY1 re-expression concomitantly with any of the three new inhibitors tested does not produce a further impairment in proliferation on any of the cells tested. Graphs show mean \pm SD of three independent experiments. $\left({ }^{\star} P<0.05,{ }^{\star \star} P<0.005\right.$, ns = non-significant). 
A

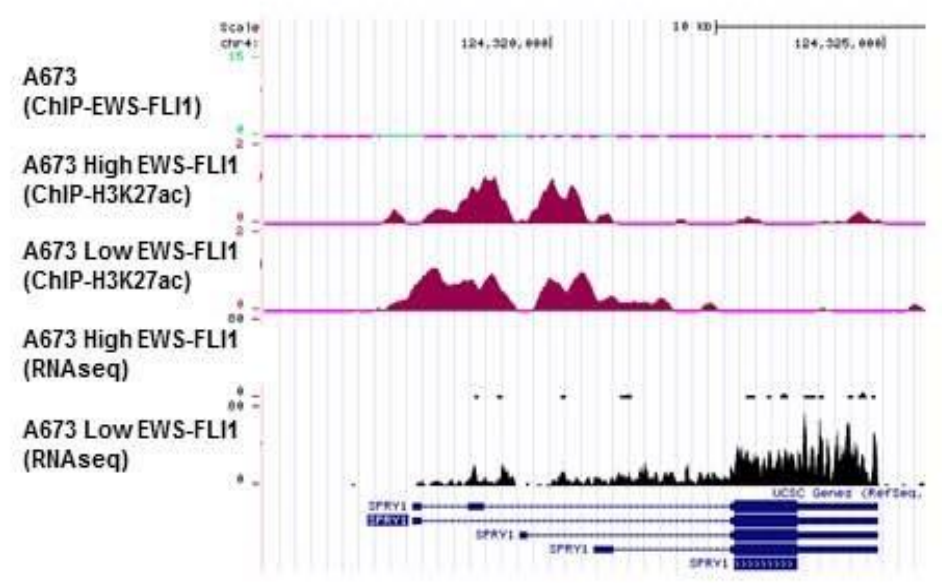

B

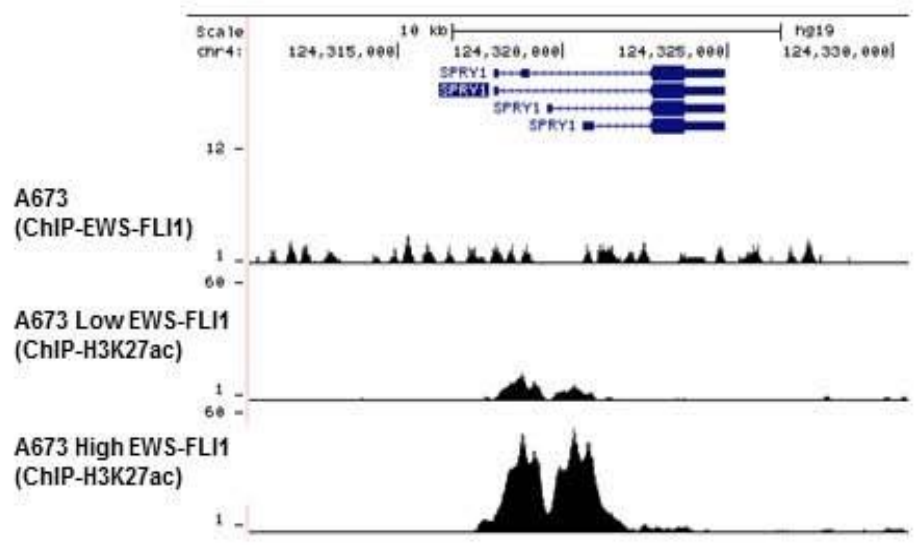

Supplementary Figure S6. Previously published ChIP-seq data suggest that SPRY1 is not a direct target of EWSFLI1. Data shown were derived from published studies in which the expression of EWS-FLI1 was downregulated by RNA interference in A673 cells. A. Genomic regions near the SPRY1 gene including ChIP-seq-EWS-FLI1 (Bilke et al., Genome Res. 2013. 23:1797-1809) and ChIP-seq-H3K27ac and RNAseq (Tomazou et al., Cell Rep. 2015. 24:1082-1095) are shown. B. Genomic region near SPRY1 including ChIP-seq data from Riggi et al., (Cancer Cell. 2014. 28-668-681). According to these studies there are no specific marks for EWS-FLI1 on the putative SPRY1 promoter region. Interestingly, EWS-FLI1 knockdown increases H3K27ac signals suggesting that an epigenetic mechanism involved in histone modifications may be involved in the regulation of SPRY1 expression. 
Cidre-Aranaz et al.

SUPPLEMENTARY TABLE 1

List of Ewing cell lines used in this study, including EWS-ETS fusion type.

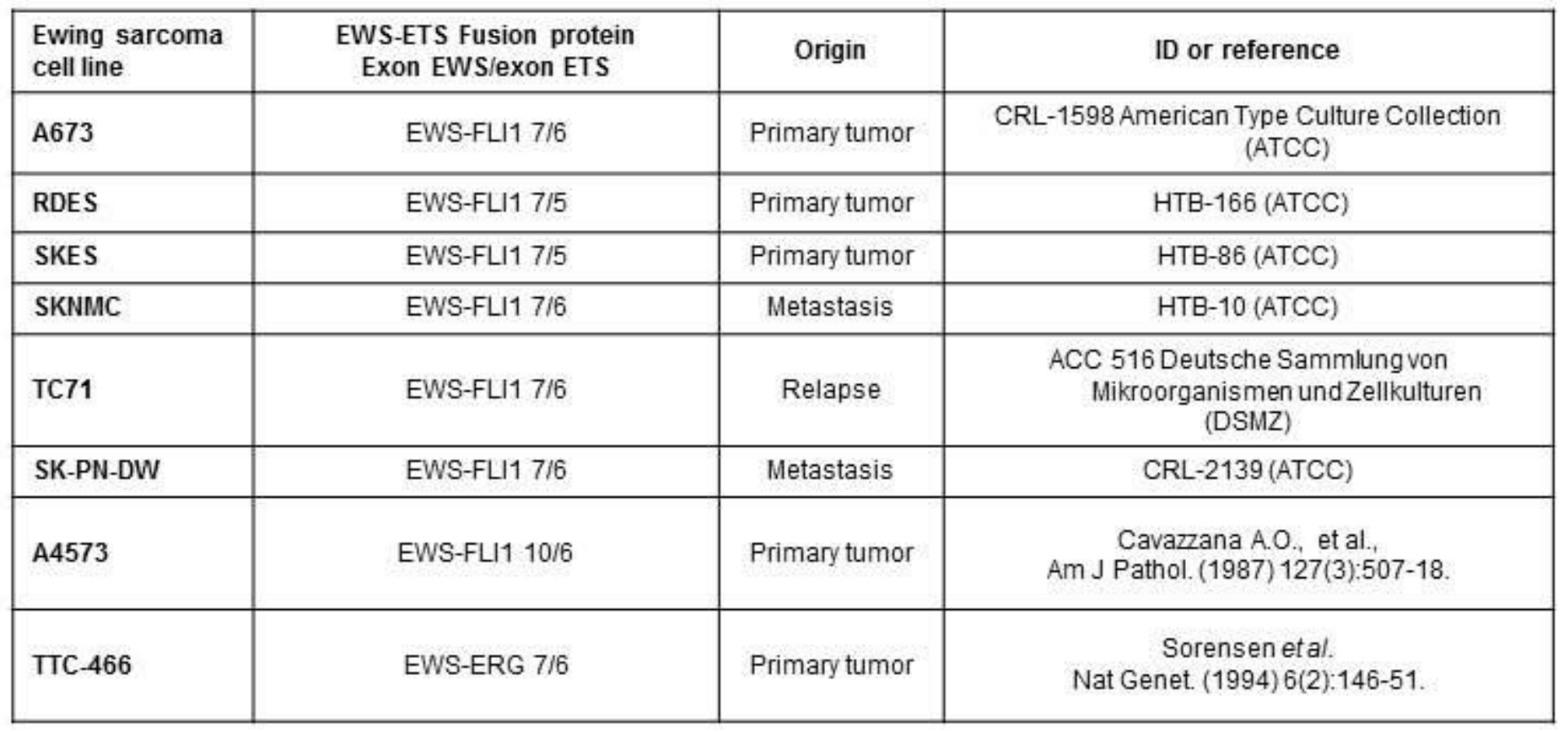


List of cell lines studied and their IC50 \pm SD when treated to four different FGF-inhibitors: PD-173074 (PD-74), PD166866 (PD-66), SU5402 (SU54), and NVP-BGJ398 (BG-98).

\begin{tabular}{|c|c|c|c|c|}
\hline & \multicolumn{4}{|c|}{ IC50 $(\boldsymbol{\mu M})$} \\
\hline Cell line & PD-74 & PD-66 & BG-98 & SU54 \\
\hline A673 & $4.03 \pm 1.04$ & $29.8 \pm 1.07$ & $2.03 \pm 1.07$ & $24.38 \pm 1.04$ \\
\hline SKNMC & $15.44 \pm 1.47$ & $32.5 \pm 1.04$ & $4.38 \pm 1.09$ & $65.88 \pm 1.04$ \\
\hline POE & $3.29 \pm 1.11$ & $2.33 \pm 1.04$ & $1.56 \pm 1.08$ & $1.53 \pm 1.11$ \\
\hline SKES & $23.33 \pm 1.03$ & $29.09 \pm 3.62$ & $4.58 \pm 1.65$ & $91.22 \pm 8.54$ \\
\hline RDES & $8.69 \pm 1.07$ & $34.95 \pm 1.07$ & $5.11 \pm 1.07$ & $50.34 \pm 1.04$ \\
\hline IMR90 & - & - & - & - \\
\hline
\end{tabular}

